\title{
Determining the Optimal Offshore Wind Power Station Using a Two-Stage MCDM-Based Spherical Fuzzy Set Approach
}

\section{Chia-Nan Wang}

National Kaohsiung University of Science and Technology

Ngoc-Ai-Thy Nguyen ( $\nabla$ thy.logistics@gmail.com )

National Kaohsiung University of Science and Technology

Thanh-Tuan Dang

National Kaohsiung University of Science and Technology

\section{Research Article}

Keywords: renewable energy, offshore wind power station, Vietnam, MCDM, SF-AHP, WASPAS, decisionmaking process

Posted Date: November 30th, 2021

DOI: https://doi.org/10.21203/rs.3.rs-1075379/v1

License: (c) (i) This work is licensed under a Creative Commons Attribution 4.0 International License. Read Full License 
2 Determining the Optimal Offshore Wind Power Station Using a Two-Stage MCDM-Based Spherical Fuzzy Set Approach

\author{
Chia-Nan Wang ${ }^{1}$, Ngoc-Ai-Thy Nguyen ${ }^{1, *}$ and Thanh-Tuan Dang ${ }^{1,2}$
}

1 Department of Industrial Engineering and Management, National Kaohsiung University of Science and Technology, Kaohsiung 80778, Taiwan; cn.wang@ nkust.edu.tw (C.-N.W.); tuandang.ise@ gmail.com (T.-T.D.)

2 Department of Logistics and Supply Chain Management, Hong Bang International University, Ho Chi Minh 723000, Vietnam

* Correspondence: thy.logistics@gmail.com (N.-A.-T.N.)

\begin{abstract}
In response to challenges from the COVID-19 pandemic and climate change to achieve the goal of ensuring sustainable economic growth, offshore wind power development not only provides a clean and sustainable source of energy but also provides opportunities for economic growth and job creation. Offshore wind energy projects have been promptly suggested in Vietnam as a result of policy advancement, with the country's excellent wind resources. The success of an offshore wind energy project is decided mainly by choosing the best location for offshore wind power station (OWPS) construction, which is a complex multicriteria decisionmaking (MCDM) problem with the coexistence of conflicting factors. There is a problem with incomplete decision information use and information loss during the decision-making process, and it is easy to overlook the interaction difficulty in a fuzzy environment. To address the complex nature of the prioritization problem posed, this study proposes a hybrid MCDM framework combining the spherical fuzzy analytical hierarchy process (SF-AHP) and weighted aggregated sum product assessment (WASPAS). SF-AHP is used in the first stage to determine the significance levels of OWPS evaluation criteria. WASPAS is then utilized to rank locations of OWPS. A comprehensive set of evaluation criteria developed based on the concept of sustainable development has been recognized by reviewing the literature review and interviewing experts to practice the two-stage MCDM model. A real case study for Vietnam is conducted to test the effectiveness of the proposed method. The best location schemes have been determined by using the decision framework. The results of the sensitivity analysis and a comparison analysis demonstrate that the decision framework is practical and robust. Ultimately, the evaluation criteria and methodology presented in this work can serve as a theoretical foundation for the advancement of offshore wind energy and coastal development.
\end{abstract}

Keywords: renewable energy; offshore wind power station; Vietnam; MCDM; SF-AHP; WASPAS; decisionmaking process

\title{
1. Introduction
}

Among various renewable energy sources, offshore wind is key to the transition to a zerocarbon energy supply in the context of the whole world facing the global fight against climate change and promoting a post-COVID-19 green recovery. According to the International Renewable Energy Agency (IRENA), the world needs to install at least $180 \mathrm{GW}$ of new wind power each year to keep the global temperature rise below $2{ }^{\circ} \mathrm{C}$ above preindustrial levels ${ }^{1}$. Located in the monsoon climate zone and shaped by a $3260 \mathrm{~km}$-long coastline, Vietnam is considered a country with great potential for offshore wind power in Asia in particular and the world in general. As reported by the World Bank, Vietnam's technical offshore wind power potential is approximately $475 \mathrm{GW}$ in water zones $200 \mathrm{~km}$ from the coastline, and the technical offshore wind power potential in the water zones ranges from $0-185 \mathrm{~km}$ up to $600 \mathrm{GW}^{2}$. With this endowment, Vietnam can achieve $11 \mathrm{GW}$ to 25 GW of offshore wind capacity by 2035 , which could create up to 700,000 jobs per year and reduce 217 million tons of carbon emissions.

Under the Vietnamese government's new Power Development Plan with a vision to 2030, a $20 \mathrm{GW}$ of renewable energy capacity, including $10 \mathrm{GW}$ of offshore wind power, aims to meet growing demand and sustainable socioeconomic development and cut $15 \%$ of carbon emissions ${ }^{3}$. Toward this goal, experts and researchers assert that policies and support mechanisms play an essential role in building national strategies and marine spatial planning for offshore wind power development. A study by Xuan Son and Thi Gam in $2021^{4}$ analyzed the current Vietnamese legal and policy framework applying offshore wind power development and Vietnamese regulations to assess the environmental impact to guarantee sustainable wind development. More specifically, 
prioritizing capacity development in line with the ability to ensure power system safety through reasonable electricity tariffs enables breakthrough supportive policies and mechanisms for offshore wind power development. Nguyen et al. ${ }^{5}$ focused on various challenges of offshore wind energy development in Vietnam, such as policy and regulatory uncertainty, construction costs, installations, sea area planning, and high investment risks. To exploit the potential of offshore wind, it is vital to pay attention to some specific characteristics because of wind's dependence on climatic and geographical conditions, and wind regimes are unevenly spread across the country. If harnessed effectively and sustainably, offshore wind can provide numerous benefits, including the valuable resource of potentially lower energy costs, the security of long-term supply of both electricity and gas, the creation of jobs and supply chain opportunities, and the improvement of environmental quality ${ }^{6}$. There have been few studies of Vietnam's offshore wind potential ${ }^{7-9}$. Studies on the location decision process for offshore wind projects are also limited.

Site selection for an offshore wind power station (OWPS) constitutes a critical phase toward a wind power project. It is a multicriteria decision-making (MCDM) problem that regards many conflicting criteria, including wind resources, construction, environmental impacts, marine spatial planning, power grid access lines, economy, and society ${ }^{10}$. With this, the decision-making of OWPS site selection encounters many difficulties. One primary concern is the ambiguity of information. It is a daunting problem to anticipate the value of each factor precisely during decisionmaking as a project prework. In addition, information loss is an unavoidable occurrence in a complex and uncertain context. As a result, how information is expressed and handled is an essential consideration in OWPS site selection. As soon as ranking methods are becoming increasingly improved, using an adequate and effective MCDM method to determine the priority of alternatives in OWPS site selection is a requisite step.

From the above perspectives, the aim of this research is to develop an MCDM-based framework for the best site selection of OWPSs. More specifically, the spherical fuzzy sets and analytical hierarchy process (SF-AHP) are integrated into the first stage to determine the significance levels of OWPS evaluation criteria, and then the weighted aggregated sum product assessment (WASPAS) is utilized to rank locations of OWPS. A comprehensive set of evaluation criteria developed based on the concept of sustainable development has been recognized through a literature review and expert opinions to practice the two-stage MCDM model. A real case study for Vietnam is carried out to validate the proposed method.

The AHP is a relative measurement method that can rank multiple alternatives by examining both qualitative and quantitative criteria based on pairwise comparisons. The method is one of the most commonly used MCDM methods to determine the relative importance (weights) of criteria and subcriteria, especially in renewable energy planning and site selection ${ }^{10}$. Even while the approach gathers data from experts, it may not precisely reflect the opinions taken. As a result, fuzzy sets theory has been integrated with AHP, and many types of fuzzy AHP have been developed to capture vagueness in preference. The effectiveness of fuzzy AHP methods has been demonstrated with increasing interest among researchers and practitioners. Such approaches have been implemented on different extensions of fuzzy set theory based on the determination of linguistic statements such as traditional fuzzy sets ${ }^{11-13}$, type- 2 fuzzy sets ${ }^{14,15}$, interval-valued fuzzy sets ${ }^{16-18}$, intuitionistic fuzzy sets ${ }^{19-21}$, neutrosophic sets ${ }^{22,23}$, Pythagorean fuzzy sets (PSF) ${ }^{24,25}$, and spherical fuzzy sets ${ }^{26,27}$. The spherical fuzzy set (SFS) is the novel set introduced in 2018 by Kutlu Gündoğdu and Kahraman ${ }^{28-31}$. It is a three-dimensional fuzzy set created as a combination of Pythagorean fuzzy sets with neutrosophic fuzzy sets. SFS can also be used to realize the criteria to handle ambiguity and fuzziness in linguistic expressions, which is a new perspective for decisionmaking in a fuzzy environment. The decision maker's indeterminacy level is specified independently of the membership and nonmembership levels of the elements in these sets. Decisionmakers define the membership function in SFS on a spherical surface to infer other fuzzy sets, with which they can allow the parameters of this membership function in a broader domain. The historical mapping of different fuzzy set extensions is displayed in Figure $1^{32-38}$.

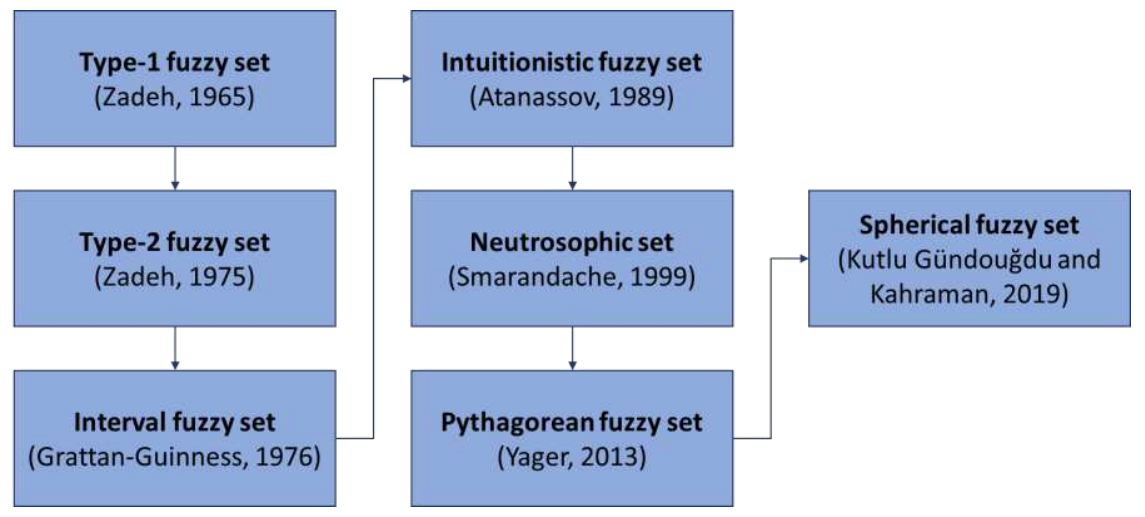


Figure 1. The historical mapping of extensions of fuzzy sets.

WASPAS was first proposed in 2012 by Zavadskas, Turskis, Antucheviciene, and Zakarevicius ${ }^{39}$ and is one of the robust new MCDM utility determining approaches. The method integrates the weighted product model (WPM) and weighted sum model (WSM), which the authors have proven to have more robust consistency and accuracy than the WPM and WSM. It also performs more accurately than independent methods in alternative ranking ${ }^{39}$. Ever since this aggregated approach appeared, a plethora of studies can be found using WASPAS in various areas. In 2013, Zolfani et al. ${ }^{40}$ applied WASPAS to business issues with a case study of selecting the best place for shopping malls located from a foresight perspective; Zavadskas et al. ${ }^{41}$ utilized the method to evaluate facade alternatives; Bagočius et al. ${ }^{42}$ used WASPAS for the selection of a deep-water port. WASPAS was employed by Vafaeipour et al. ${ }^{43}$ for the region priority problem for solar project implementation. Badalpur and Nurbakhsh ${ }^{44}$ evaluated the risks of a road construction project by taking the merits of the WASPAS method. To solve the supplier selection problem, Singh and Modgil ${ }^{45}$ used WASPAS to finalize the best supplier in the cement industry. Considering the increasing trend of the delivery industry, in the most recent studies, Nguyen et al. ${ }^{46}$ utilized WASPAS to select the best online food delivery companies; Wang et al. ${ }^{47}$ used the method to evaluate sustainable last-mile delivery for e-commerce companies.

The remainder of this paper is structured as follows. Section 2 summarizes MCDM methodologies applied to the site selection of OWPS and critical evaluation criteria used in the studies. In Section 3, the implementation of the proposed hybrid methodology is explained in detail. In Section 4 , the OWPS case study analysis in Vietnam is demonstrated, and then the results validation is conducted in Section 5. Section 6 contains concluding remarks.

\section{Literature Review}

There have been a moderate number of significant studies on OWPS selection in the last ten years, in which MCDM approaches have shown remarkable results in many case evaluations worldwide. Some widely applied techniques in OWPS evaluation include analytic hierarchy process (AHP), analytic network process (ANP), technique for order of preference by similarity to ideal solution (TOPSIS), elimination and choice expressing the reality (ELECTRE), decision making trial and evaluation laboratory (DEMATEL), preference ranking organization method for enrichment evaluations (PROMETHEE). Fuzzy sets theory and grey theory are frequently integrated with MCDM methods to address uncertain and incomplete information/preference. Chaouachi et al. ${ }^{48}$ presented the multicriteria selection of offshore wind farms with a case study for the Baltic States; the AHP method was utilized to consider economic investment, security aspects, operation costs and capacity performances. Fetanat and Khorasaninejad ${ }^{12}$ developed a novel hybrid MCDM approach based on the fuzzy ANP, fuzzy DEMATEL, and fuzzy ELECTRE to assist in the site selection of offshore wind farms in Iran; six criteria (depth and height, environment, distance to facilities, economic aspects, wind resources, and culture) were determined with related subcriteria. A decision framework combining triangular intuitionistic fuzzy numbers (TIFNs), ANP and PROMETHEE was proposed by $\mathrm{Wu}$ et al. ${ }^{21}$ to select the best location for OWPS in a Chinese case study considering six criteria (wind resources, environment, economic, construction, society, and risks) and the related subcriteria. Lo et al. ${ }^{49}$ proposed the grey DEMATEL-based ANP model for location optimization for OWPSs in Taiwan, concerning the following dimensions: wind conditions, marine conditions, shore support conditions, economic impacts, environmental and ecological impacts, and societal impacts. Table 1 provides an overview of studies on the site selection of offshore wind farms.

Table 1. Overview of studies on the site selection of offshore wind farms.

\begin{tabular}{ccccc}
\hline No & Authors & MCDM Technique & Location & Main findings \\
\hline 1 & $\begin{array}{c}\text { Fetanat and Khorasa- } \\
\text { ninejad (2015) }\end{array}$ & $\begin{array}{c}\text { Fuzzy ANP, fuzzy DEMATEL, } \\
\text { and fuzzy ELECTRE }\end{array}$ & Iran & $\begin{array}{c}\text { The optimal site can be chosen from } \\
\text { four options, and the method's robust- } \\
\text { ness is proven. }\end{array}$ \\
\hline 3 & Wu et al. (2016) & ELECTRE-III & China & $\begin{array}{c}\text { The developed methodology for OWPS } \\
\text { site selection is both valid and practical. }\end{array}$ \\
\hline & Vasileiou et al. (2017) & AHP & $\begin{array}{c}\text { The finding illustrates the potential for } \\
\text { offshore wind and wave energy deploy- } \\
\text { ment in Greece, particularly in Crete's } \\
\text { offshore areas and a longitudinal zone } \\
\text { extending from the north-central to the } \\
\text { central Aegean. }\end{array}$ \\
\hline
\end{tabular}



map for appropriate offshore wind locations, with three high wind suitable areas around the Red Sea found with the minimum restrictions.

6 Wu et al. (2018)

Fuzzy AHP

China
The approach is applied to a real-world site selection of offshore wind farms in the Eastern China Sea; it illustrates that maritime safety is a predominant factor.

\begin{tabular}{|c|c|c|c|c|}
\hline 7 & Wu et al. (2020) & Fuzzy ANP-PROMETHEE & China & $\begin{array}{l}\text { The decision model proposed is feasible } \\
\text { and valid. }\end{array}$ \\
\hline 8 & Abdel-Basset et al. (2021) & AHP and PROMETHEE-II & Egypt & $\begin{array}{l}\text { Rigorous methodological support is pre- } \\
\text { sented for site selection to achieve bene- } \\
\text { fits in coastal management. }\end{array}$ \\
\hline 9 & Lo et al. (2021) & Grey DEMATEL-based ANP & Taiwan & $\begin{array}{l}\text { Optimal sites are not only determined by } \\
\text { their wind resources and costs; decision- } \\
\text { makers must pay particular attention to } \\
\text { appropriate strategies and policy plan- } \\
\text { ning toward OWPS. }\end{array}$ \\
\hline
\end{tabular}

Since investment is huge in the installment of OWPSs, it is critical to identify and prioritize viable locations prior to developing expensive OWPSs, as such decisions would assist in achieving the best productivity, reducing socioeconomic costs, minimizing environmental consequences, optimizing social benefits, and developing the concerned regions toward sustainability. The recognition of resources, conditions, economic and environmental dimensions, societal impacts, and political factors is the preliminary and crucial phase for establishing new offshore wind plants. Only a few have taken sustainability issues into account from previous works when devising a site selection framework for offshore wind farms. In this research, the decision criteria based on the perspective of sustainability are extracted through a literature review and recognized by experts, as shown in Table 2.

Table 2. Summary of criteria considered from the literature reviewed.

\begin{tabular}{|c|c|c|c|c|c|c|c|c|c|}
\hline Criteria & $\begin{array}{c}\text { Fetanat and } \\
\text { Khorasa- } \\
\text { ninejad } \\
(2015)\end{array}$ & $\begin{array}{c}\text { Wu et } \\
\text { al. } \\
(2016)\end{array}$ & $\begin{array}{l}\text { Vasile- } \\
\text { iou et } \\
\text { al. } \\
(2017)\end{array}$ & $\begin{array}{c}\text { Chaouachi } \\
\text { et al. } \\
(2017)\end{array}$ & $\begin{array}{l}\text { Mahdy } \\
\text { and } \\
\text { Bahaj } \\
(2018)\end{array}$ & $\begin{array}{c}\text { Wu et } \\
\text { al. } \\
(2018)\end{array}$ & $\begin{array}{c}\text { Wu et } \\
\text { al. } \\
(2020)\end{array}$ & $\begin{array}{c}\text { Abdel-Bas- } \\
\text { set et al. } \\
(2021)\end{array}$ & $\begin{array}{l}\text { Lo et } \\
\text { al. } \\
(2021)\end{array}$ \\
\hline Wind resources & $\mathrm{v}$ & $\mathrm{v}$ & $\mathrm{v}$ & $\mathrm{v}$ & $\mathrm{v}$ & $\mathrm{v}$ & $\mathrm{v}$ & $\mathrm{v}$ & $\mathrm{v}$ \\
\hline Seawater depth & $\mathrm{v}$ & $\mathrm{v}$ & $\mathrm{v}$ & $\mathrm{v}$ & $\mathrm{v}$ & $\mathrm{v}$ & & $\mathrm{v}$ & $\mathrm{v}$ \\
\hline $\begin{array}{l}\text { Undersea geolog- } \\
\text { ical conditions }\end{array}$ & & $\mathrm{v}$ & & & & & $\mathrm{v}$ & $\mathrm{v}$ & $\mathrm{v}$ \\
\hline Marine conditions & $\mathrm{v}$ & $\mathrm{v}$ & & & & $\mathrm{v}$ & $\mathrm{v}$ & $\mathrm{v}$ & $\mathrm{v}$ \\
\hline $\begin{array}{c}\text { Environmental } \\
\text { protection }\end{array}$ & $\mathrm{v}$ & $\mathrm{v}$ & & $\mathrm{v}$ & & & $\mathrm{v}$ & $\mathrm{v}$ & $\mathrm{v}$ \\
\hline Distance to shore & $\mathrm{v}$ & $\mathrm{v}$ & $\mathrm{v}$ & $\mathrm{v}$ & $\mathrm{v}$ & $\mathrm{v}$ & & $\mathrm{v}$ & $\mathrm{v}$ \\
\hline $\begin{array}{l}\text { Electricity net- } \\
\text { works }\end{array}$ & $\mathrm{V}$ & $\mathrm{v}$ & $\mathrm{V}$ & $\mathrm{V}$ & & & & $\mathrm{v}$ & \\
\hline
\end{tabular}




\begin{tabular}{|c|c|c|c|c|c|c|c|c|}
\hline Traffic condition & & $\mathrm{v}$ & $\mathrm{V}$ & $\mathrm{V}$ & $\mathrm{v}$ & $\mathrm{v}$ & $\mathrm{v}$ & $\mathrm{v}$ \\
\hline Profit & $\mathrm{v}$ & $\mathrm{v}$ & & & & $\mathrm{v}$ & $\mathrm{v}$ & $\mathrm{v}$ \\
\hline $\begin{array}{l}\text { Construction, op- } \\
\text { eration, and } \\
\text { maintenance costs }\end{array}$ & & $\mathrm{v}$ & & & & $\mathrm{V}$ & $\mathrm{V}$ & $\mathrm{v}$ \\
\hline Local subsidies & & $\mathrm{v}$ & & & & & & \\
\hline Job creation & & $\mathrm{v}$ & & & & $\mathrm{v}$ & $\mathrm{v}$ & $\mathrm{v}$ \\
\hline Policy planning & & & & & & $\mathrm{V}$ & $\mathrm{V}$ & $\mathrm{v}$ \\
\hline
\end{tabular}

In this paper, for the first time, spherical fuzzy sets, AHP and WASPAS, are combined for the site selection of OWPS. To the best of our knowledge, the proposed integrated approach is novel and has not been reported elsewhere. The paper's contributions are presented as follows:

- This paper presents an effective evaluation model for locating offshore wind power facilities. To fulfill the awareness of sustainable development, the model contains a comprehensive set of sustainability indicators.

- The calculations for weighting the criteria are performed using spherical fuzzy sets for a broader linguistic scale of experts' judgments, which completely reflects the decisionmaking process in uncertain environments. WASPAS has the capability and more accuracy in ranking the alternatives.

- A thorough investigation of the OWPS site selection in Vietnam is solved for the first time, with a real case study used to test the robustness of the proposed model.

- The paper is directed toward providing a recommendation for the government and practitioners for offshore wind farm site selection.

\section{Materials and Methods}

\subsection{Framework of the Research}

This paper introduces an effective integrated assessment model for evaluating and selecting the optimal offshore wind power station (OWPS) case study in Vietnam. The proposed framework includes two stages, which are described in Figure 2. In the first stage, the SF-AHP model determines each criterion's fuzzy weight and crisp weight. The spherical fuzzy set, represented by linguistics number, is involved in the AHP model to manage the uncertainties and vagueness by the experts' judgment. The consistency of the pairwise comparison matrices is checked to ensure the model's validation. In the second stage, the wind power locations are ranked by using the WASPAS model. Next, a comparison with the existing area, sensitivity analysis of the threshold value, and comparative analysis of the methods are performed to demonstrate the feasibility and applicability of the proposed model. 


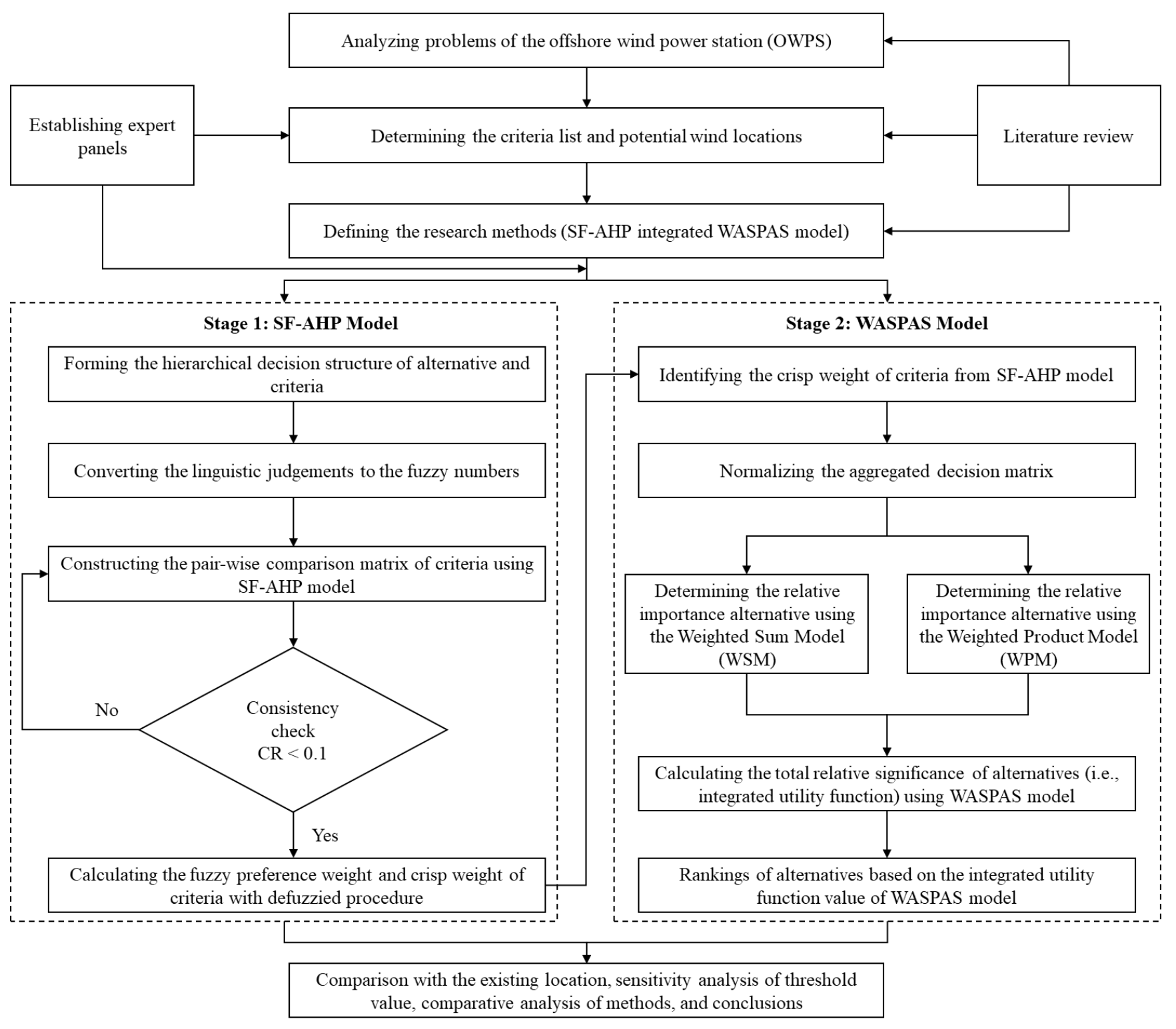

Figure 2. The proposed framework of the research.

\subsection{Spherical Fuzzy Analytical Hierarchy Process (SF-AHP)}

Spherical fuzzy sets (SFS) were newly developed by Kutlu Gündouğdu and Kahraman ${ }^{50}$ to handle uncertainty during the quantification of expert judgments. The differences among the intuitionistic fuzzy set, Pythagorean fuzzy set, neutrosophic set, and spherical fuzzy sets ${ }^{51}$ are visualized in Figure 3. The SFS consists of three parameters: membership, nonmembership, and hesitancy degrees. The basic procedures of SFS are presented as follows. 


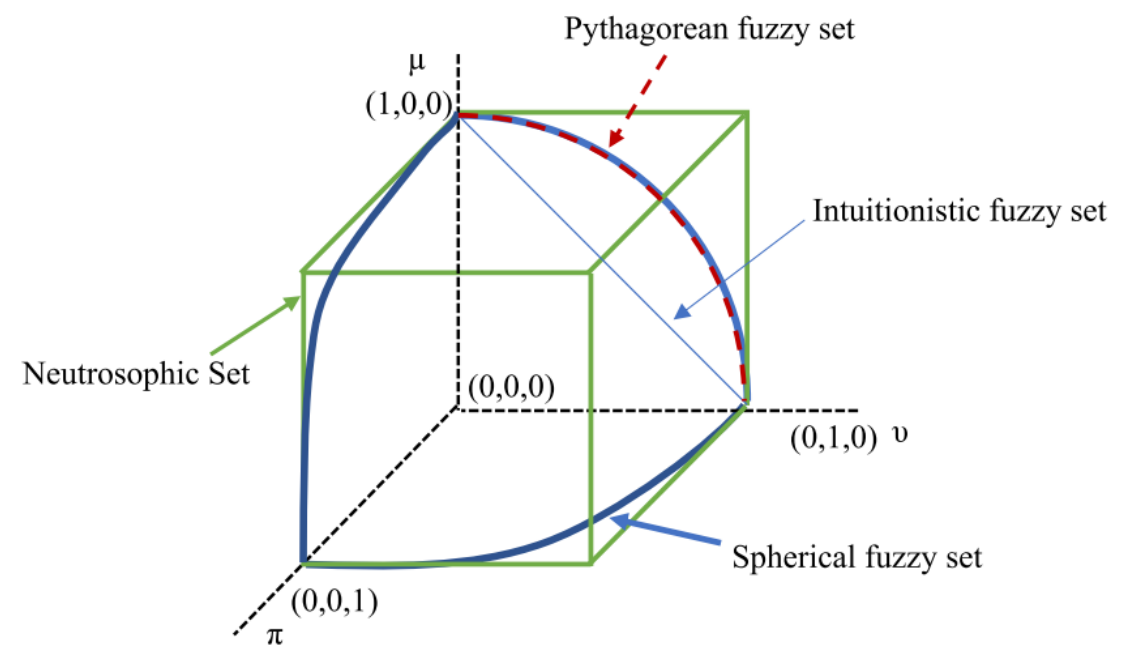

Figure 3. Geometric representations of spherical fuzzy sets in 3D space.

Definition 1. Spherical fuzzy set (SFS) $\tilde{A}_{S}$ is described as follows:

$$
\tilde{A}_{S}=\left\{x,\left(\mu_{\tilde{A}_{S}}(x), v_{\tilde{A}_{S}}(x), \pi_{\tilde{A}_{S}}(x)\right) \mid x \in X\right\}
$$

where $\tilde{A}_{S}$ represents a spherical fuzzy set of the universe $X$ :

$$
\mu_{\tilde{A}_{S}}(x): X \rightarrow[0,1], v_{\tilde{A}_{S}}(x): X \rightarrow[0,1], \pi_{\tilde{A}_{S}}(x): X \rightarrow[0,1]
$$

and

$$
0 \leq \mu_{\tilde{A}_{S}}^{2}(x)+v_{\tilde{A}_{S}}^{2}(x)+\pi_{\tilde{A}_{S}}^{2}(x) \leq 1
$$

where $\forall x \in X$, and for each $x, \mu_{\tilde{A}_{S}}(x), v_{\tilde{A}_{S}}(x)$, and $\pi_{\tilde{A}_{S}}(x)$ represent the membership, nonmembership, and hesitancy levels of $x$ to $\tilde{A}_{S}$, respectively.

Definition 2. Let $\tilde{A}_{S}=\left(\mu_{\tilde{A}_{S}}, v_{\tilde{A}_{S}}, \pi_{\tilde{A}_{S}}\right)$ and $\tilde{B}_{S}=\left(\mu_{\tilde{B}_{S}}, v_{\tilde{B}_{S}}, \pi_{\tilde{B}_{S}}\right)$ be two SFS. Some arithmetic operations of SFS are described as follows:

- Union:

$$
\begin{aligned}
\tilde{A}_{S} \cup \tilde{B}_{S}=\{ & \max \left\{\mu_{\tilde{A}_{S}}, \mu_{\tilde{B}_{S}}\right\}, \min \left\{v_{\tilde{A}_{S}}, v_{\tilde{B}_{S}}\right\}, \min \{(1 \\
& -\left(\left(\max \left\{\mu_{\tilde{A}_{S}}, \mu_{\tilde{B}_{S}}\right\}\right)^{2}\right. \\
& \left.\left.\left.\left.+\left(\min \left\{v_{\tilde{A}_{S}}, v_{\tilde{B}_{S}}\right\}\right)^{2}\right)\right)^{1 / 2}, \max \left\{\pi_{\tilde{A}_{S}}, \pi_{\tilde{B}_{S}}\right\}\right\}\right\}
\end{aligned}
$$

- Intersection:

$$
\begin{aligned}
\tilde{A}_{S} \cap \tilde{B}_{S}=\{ & \min \left\{\mu_{\tilde{A}_{S}}, \mu_{\tilde{B}_{S}}\right\}, \max \left\{v_{\tilde{A}_{S}}, v_{\tilde{B}_{S}}\right\}, \max \{(1 \\
& -\left(\left(\min \left\{\mu_{\tilde{A}_{S}}, \mu_{\tilde{B}_{S}}\right\}\right)^{2}\right. \\
& \left.\left.\left.\left.+\left(\max \left\{v_{\tilde{A}_{S}}, v_{\tilde{B}_{S}}\right\}\right)^{2}\right)\right)^{1 / 2}, \min \left\{\pi_{\tilde{A}_{S}}, \pi_{\tilde{B}_{S}}\right\}\right\}\right\}
\end{aligned}
$$

- Addition:

$$
\begin{aligned}
\tilde{A}_{S} \oplus \tilde{B}_{S}= & \left\{\left(\mu_{\tilde{A}_{S}}^{2}+\mu_{\tilde{B}_{S}}^{2}-\mu_{\tilde{A}_{S}}^{2} \mu_{\tilde{B}_{S}}^{2}\right)^{1 / 2}, v_{\tilde{A}_{S} v_{\tilde{B}_{S}}}\left(\left(1-\mu_{\tilde{B}_{S}}^{2}\right) \pi_{\tilde{A}_{S}}^{2}+(1\right.\right. \\
& \left.\left.\left.-\mu_{\tilde{A}_{S}}^{2}\right) \pi_{\tilde{B}_{S}}^{2}-\pi_{\tilde{A}_{S}}^{2} \pi_{\tilde{B}_{S}}^{2}\right)^{1 / 2}\right\}
\end{aligned}
$$

- Multiplication:

$$
\begin{aligned}
\tilde{A}_{S} \otimes \tilde{B}_{S}= & \left\{\mu_{\tilde{A}_{S}}^{2} \mu_{\tilde{B}_{S^{\prime}}}^{2}\left(v_{\tilde{A}_{S}}^{2}+v_{\tilde{B}_{S}}^{2}-v_{\tilde{A}_{S}}^{2} v_{\tilde{B}_{S}}^{2}\right)^{1 / 2},\left(\left(1-v_{\tilde{B}_{S}}^{2}\right) \pi_{\tilde{A}_{S}}^{2}+(1\right.\right. \\
& \left.\left.\left.-v_{\tilde{A}_{S}}^{2}\right) \pi_{\tilde{B}_{S}}^{2}-\pi_{\tilde{A}_{S}}^{2} \pi_{\tilde{B}_{S}}^{2}\right)^{1 / 2}\right\}
\end{aligned}
$$

- $\quad$ Multiplication by a scalar; $\lambda>0$ :

$$
\lambda \cdot \tilde{A}_{S}=\left\{\left(1-\left(1-\mu_{\tilde{A}_{S}}^{2}\right)^{\lambda}\right)^{1 / 2}, v_{\tilde{A}_{S}}^{\lambda}\left(\left(1-\mu_{\tilde{A}_{S}}^{2}\right)^{\lambda}-\left(1-\mu_{\tilde{A}_{S}}^{2}-\pi_{\tilde{A}_{S}}^{2}\right)^{\lambda}\right)^{1 / 2}\right\}
$$

- $\quad$ Power of $\tilde{A}_{S} ; \lambda>0$ : 


$$
\tilde{A}_{S}^{\lambda}=\left\{\mu_{\tilde{A}_{S}}^{\lambda}\left(1-\left(1-v_{\widetilde{A}_{S}}^{2}\right)^{\lambda}\right)^{1 / 2},\left(\left(1-v_{\widetilde{A}_{S}}^{2}\right)^{\lambda}-\left(1-v_{\tilde{A}_{S}}^{2}-\pi_{\tilde{A}_{S}}^{2}\right)^{\lambda}\right)^{1 / 2}\right\}
$$

Definition 3. For SFSs $\tilde{A}_{S}=\left(\mu_{\tilde{A}_{S}}, v_{\tilde{A}_{S}}, \pi_{\tilde{A}_{S}}\right)$ and $\tilde{B}_{S}=\left(\mu_{\tilde{B}_{S}}, v_{\tilde{B}_{S}}, \pi_{\tilde{B}_{S}}\right)$, the following are valid under the condition $\lambda, \lambda_{1}, \lambda_{2}>0$ :

$$
\begin{gathered}
\tilde{A}_{S} \oplus \tilde{B}_{S}=\tilde{B}_{S} \oplus \tilde{A}_{S} \\
\tilde{A}_{S} \otimes \tilde{B}_{S}=\tilde{B}_{S} \otimes \tilde{A}_{S} \\
\lambda\left(\tilde{A}_{S} \oplus \tilde{B}_{S}\right)=\lambda \tilde{A}_{S} \oplus \lambda \tilde{B}_{S} \\
\lambda_{1} \tilde{A}_{S} \oplus \lambda_{2} \tilde{A}_{S}=\left(\lambda_{1}+\lambda_{2}\right) \tilde{A}_{S} \\
\left(\tilde{A}_{S} \otimes \tilde{B}_{S}\right)^{\lambda}=\tilde{A}_{S}^{\lambda} \otimes \tilde{B}_{S}^{\lambda} \\
\tilde{A}_{S}^{\lambda_{1}} \otimes \tilde{A}_{S}^{\lambda_{2}}=\tilde{A}_{S}^{\lambda_{1}+\lambda_{2}}
\end{gathered}
$$

Definition 4. For the spherical weighted arithmetic mean (SWAM) with respect to, $w=$ $\left(w_{1}, w_{2}, \ldots, w_{n} w_{i} \in[0,1]\right.$, and $\sum_{i=1}^{n} w_{i}=1$, the SWAM is calculated as follows:

$$
\begin{gathered}
\operatorname{SWAM}_{w}\left(\tilde{A}_{S 1}, \ldots, \tilde{A}_{S n}\right)=w_{1} \tilde{A}_{S 1}+w_{2} \tilde{A}_{S 2}+\ldots+w_{n} \tilde{A}_{S n}=\left\{\left[1-\prod_{i=1}^{n}\left(1-\mu_{\tilde{A}_{S i}}^{2}\right)^{w_{i}}\right]^{1 / 2},\right. \\
\left.\prod_{i=1}^{n} v_{\tilde{A}_{S i}}^{w_{i}},\left[\prod_{i=1}^{n}\left(1-\mu_{\tilde{A}_{S i}}^{2}\right)^{w_{i}}-\prod_{i=1}^{n}\left(1-\mu_{\tilde{A}_{S i}}^{2}-\pi_{\tilde{A}_{S i}}^{2}\right)^{w_{i}}\right]^{1 / 2}\right\}
\end{gathered}
$$

Definition 5. For the spherical weighted geometric mean (SWGM) with respect to, $w=$ $\left(w_{1}, w_{2}, \ldots, w_{n}\right), w_{i} \in[0,1]$ and $\sum_{i=1}^{n} w_{i}=1$, the SWGM is calculated as follows:

$$
\begin{aligned}
S_{W G} M_{w}\left(\tilde{A}_{S 1}, \ldots, \ddot{A}_{S n}\right)_{n}=\tilde{A}_{S 1}^{w_{1}}+\tilde{A}_{S 2}^{w_{2}}+\ldots+\tilde{A}_{S n}^{w_{n}} \\
=\prod_{i=1}^{n} \mu_{\tilde{A}_{S i}}^{w_{i}},\left[1-\prod_{i=1}^{n}\left(1-v_{\tilde{A}_{S i}}^{2}\right)^{w_{i}}\right]^{1 / 2},\left[\prod_{i=1}^{n}\left(1-v_{\tilde{A}_{S i}}^{2}\right)^{w_{i}}\right. \\
\left.-\prod_{i=1}^{n}\left(1-v_{\tilde{A}_{S i}}^{2}-\pi_{\tilde{A}_{S i}}^{2}\right)^{w_{i}}\right]^{1 / 2}
\end{aligned}
$$

In this paper, the SF-AHP model was used to determine the criteria weights of the list of criteria for building the power plant of wind offshore with a case study in Vietnam. The SF-AHP model has five steps, which are described as follows.

Step 1: A hierarchical decision tree is divided into three levels, including the research goal (level 1), list of criteria $C=\left\{C_{1}, C_{2}, \ldots C_{n}\right\}$ (level 2), and location alternatives $A=$ $\left\{A_{1}, A_{2}, \ldots A_{m}\right\}$ (within $m \geq 2$ ).

Step 2: Pairwise comparison matrices are performed regarding linguistic terms, as shown in Table 3. The score indices (SI) are determined by Equations (18) and (19):

$$
S I=\sqrt{\left|100 *\left[\left(\mu_{\tilde{A}_{S}}-\pi_{\tilde{A}_{S}}\right)^{2}-\left(v_{\tilde{A}_{S}}-\pi_{\tilde{A}_{S}}\right)^{2}\right]\right|}
$$

for the AMI, VHI, HI, SMI, and EI.

$$
\frac{1}{S I}=\frac{1}{\sqrt{\left|100 *\left[\left(\mu_{\tilde{A}_{S}}-\pi_{\tilde{A}_{S}}\right)^{2}-\left(v_{\tilde{A}_{S}}-\pi_{\tilde{A}_{S}}\right)^{2}\right]\right|}}
$$

for the EI, SLI, LI, VLI, and ALI.

Table 3. SF-AHP linguistic terms used for pairwise comparisons.

\begin{tabular}{cccc}
\hline Linguistics Terms & Symbol & $\begin{array}{c}\text { Fuzzy num- } \\
\operatorname{ber}(\boldsymbol{\mu}, \boldsymbol{v}, \boldsymbol{\pi})\end{array}$ & Score Index (SI) \\
\hline Absolutely more importance & AMI & $(0.9,0.1,0.0)$ & 9 \\
\hline
\end{tabular}




\begin{tabular}{cclc}
\hline Very high importance & VHI & $(0.8,0.2,0.1)$ & 7 \\
High importance & HI & $(0.7,0.3,0.2)$ & 5 \\
Slightly more importance & SMI & $(0.6,0.4,0.3)$ & 3 \\
Equally importance & EI & $(0.5,0.4,0.4)$ & 1 \\
Slightly low importance & SLI & $(0.4,0.6,0.3)$ & $1 / 3$ \\
Low importance & LI & $(0.3,0.7,0.2)$ & $1 / 5$ \\
Very low importance & VLI & $(0.2,0.8,0.1)$ & $1 / 7$ \\
Absolutely low importance & ALI & $(0.1,0.9,0.0)$ & $1 / 9$ \\
\hline
\end{tabular}

Step 3: A consistency check is required for pairwise comparison matrices by the consistency ratio (CR), where the CR must be less than $10 \%$.

Step 4: Compute the criterion and alternative spherical fuzzy weights. Determine the weight of each alternative using the SWAM operator using Equation (20):

$$
\begin{aligned}
& S_{W A M}\left(\tilde{A}_{S 1}, \ldots, \tilde{A}_{S n}\right)=w_{1} \tilde{A}_{S 1}+w_{2} \tilde{A}_{S 2}+\ldots+w_{n} \tilde{A}_{S n} \\
&=\left\langle\left[1-\prod_{i=1}^{n}\left(1-\mu_{\tilde{A}_{S i}}^{2}\right)^{w_{i}}\right]^{1 / 2},\right. \\
&\left.\prod_{i=1}^{n} v_{\tilde{A}_{S i}}^{w_{i}},\left[\prod_{i=1}^{n}\left(1-\mu_{\tilde{A}_{S i}}^{2}\right)^{w_{i}}-\prod_{i=1}^{n}\left(1-\mu_{\tilde{A}_{S i}}^{2}-\pi_{\tilde{A}_{S i}}^{2}\right)^{w_{i}}\right]^{1 / 2}\right\rangle
\end{aligned}
$$

where $w=1 / n$.

Step 5: The final ranking orders for the alternatives are estimated using the defuzzification global weights in Equation (21):

$$
S\left(\widetilde{w}_{j}^{s}\right)=\sqrt{\left|100 *\left[\left(3 \mu_{\tilde{A}_{S}}-\frac{\pi_{\tilde{A}_{S}}}{2}\right)^{2}-\left(\frac{v_{\tilde{A}_{S}}}{2}-\pi_{\tilde{A}_{S}}\right)^{2}\right]\right|}
$$

Normalize the criteria weights using Equation (22) and apply the spherical fuzzy multiplication shown in Equation (23):

$$
\begin{gathered}
\bar{w}_{j}^{S}=\frac{S\left(\widetilde{w}_{j}^{S}\right)}{\sum_{j=1}^{n} S\left(\widetilde{w}_{j}^{S}\right)} \\
\tilde{A}_{S_{i j}}=\bar{w}_{j}^{S} \cdot \tilde{A}_{S_{i}}=\left\langle\left(1-\left(1-\mu_{\tilde{A}_{S}}^{2}\right)^{w_{j}^{-s}}\right)^{1 / 2}, v_{\tilde{A}_{S}}^{\bar{w}_{j}^{S}},\left(\left(1-\mu_{\tilde{A}_{S}}^{2}\right)^{w_{j}^{-s}}\right.\right. \\
\left.\left.-\left(1-\mu_{\tilde{A}_{S}}^{2}-\pi_{\tilde{A}_{S}}^{2}\right)^{w_{j}^{-s}}\right)^{1 / 2}\right\rangle \forall i
\end{gathered}
$$

The final SF-AHP score $(\tilde{F})$ for each alternative $A_{i}$ is obtained by carrying out spherical fuzzy arithmetic addition over each global preference weight, as given in Equation (24):

$$
\begin{gathered}
\tilde{F}=\sum_{j=1}^{n} \tilde{A}_{S_{i j}}=\tilde{A}_{S_{i 1}} \oplus \tilde{A}_{S_{i 2}} \ldots \oplus \tilde{A}_{S_{i n}} \forall i \\
\text { i.e., } \quad \tilde{A}_{S_{11}} \oplus \tilde{A}_{S_{12}}=\left\langle\left(\mu_{\tilde{A}_{S_{11}}}^{2}+\mu_{\tilde{A}_{S_{12}}}^{2}-\mu_{\tilde{A}_{S_{11}}}^{2} \mu_{\tilde{A}_{S_{12}}}^{2}\right)^{1 / 2}, v_{\tilde{A}_{S_{11}}} v_{\tilde{A}_{S_{12}}},((1-\right. \\
\left.\left.\left.\mu_{\tilde{A}_{S_{12}}}^{2}\right) \pi_{\tilde{A}_{S_{11}}}^{2}+\left(1-\mu_{\tilde{A}_{S_{11}}}^{2}\right) \pi_{\tilde{A}_{S_{12}}}^{2}-\pi_{\tilde{A}_{S_{11}}}^{2} \pi_{\tilde{A}_{S_{12}}}^{2}\right)^{1 / 2}\right\rangle
\end{gathered}
$$

The second way to follow is to continue without defuzzification. In this case, spherical fuzzy global preference weights are calculated using Equation (25):

$$
\begin{gathered}
\prod_{j=1}^{n} \tilde{A}_{S_{i j}}=\tilde{A}_{S_{i 1}} \otimes \tilde{A}_{S_{i 2}} \ldots \otimes \tilde{A}_{S_{i n}} \forall i \\
\text { i.e, } \tilde{A}_{S_{11}} \otimes \tilde{A}_{S_{12}}=\left\langle\left(\mu_{\tilde{A}_{S_{11}}} \mu_{\tilde{A}_{S_{12}}},\left(v_{\tilde{A}_{S_{11}}}^{2}+v_{\tilde{A}_{S_{12}}}^{2}-v_{\tilde{A}_{S_{11}}}^{2} v_{\tilde{A}_{S_{12}}}^{2}\right)^{1 / 2},\left(\left(1-v_{\tilde{A}_{S_{12}}}^{2}\right) \pi_{\tilde{A}_{S_{11}}}^{2}+\right.\right.\right. \\
\left.\left.\left(1-v_{\tilde{A}_{S_{11}}}^{2}\right) \pi_{\tilde{A}_{S_{12}}}^{2}-\pi_{\tilde{A}_{S_{11}}}^{2} \pi_{\tilde{A}_{S_{12}}}^{2}\right)^{1 / 2}\right\rangle
\end{gathered}
$$

Sort the alternative according to their defuzzified final ratings. The highest value denotes the optimal option.

\subsection{Weighted Aggregated Sum Product Assessment (WASPAS)}

The WASPAS method was proposed in $2012^{39}$ and is the combination of the weighted product model (WPM) and weighted sum model (WSM); the procedure is explained as follows:

Step 1: A decision matrix is constructed $X=\left[x_{i j}\right]_{m \times n}$, where $x_{i j}$ is the performance of the $i^{\text {th }}$ alternative to the $j^{\text {th }}$ criterion, $m$ is the number of alternatives and $n$ is the number of criteria.

Step 2: Equations (26) and (27) are used to normalize the decision matrix:

For maximizing criteria (benefit): 


$$
\bar{X}_{i j}=\frac{x_{i j}}{\max _{i} x_{i j}}, \text { such that } i=1,2, \ldots, m ; j=1,2, \ldots, n
$$

For minimizing criteria (nonbenefit):

$$
\bar{X}_{i j}=\frac{\min _{i} x_{i j}}{x_{i j}}, \text { such that } i=1,2, \ldots, m ; j=1,2, \ldots, n
$$

Step 3: Equation (28) is used to calculate the relative importance of the alternative using the weighted sum model (WSM):

$$
Q_{i}^{(1)}=\sum_{j=1}^{n} \bar{X}_{i j} w_{j}, \text { such that } i=1,2, \ldots, m
$$

where $w_{j}$ is the weight (relative importance) of the $j^{\text {th }}$ criterion.

Step 4: The relative importance of the alternative is then calculated using the weighted product model (WPM), as shown in Equation (29):

$$
Q_{i}^{(2)}=\prod_{j=1}^{n}\left(\bar{X}_{i j}\right)^{w_{j}}, \text { such that } i=1,2, \ldots, m
$$

where $w_{j}$ is the weight (relative importance) of the $j^{t h}$ criterion. In this paper, $w_{j}$ is obtained from SF-AHP model. (30):

Step 5: The integrated utility function of the WASPAS model is calculated using Equation

$$
Q_{i}=\lambda Q_{i}^{(1)}+(1-\lambda) Q_{i}^{(2)}=\lambda \sum_{j=1}^{n} \bar{X}_{i j} w_{j}+(1-\lambda) \prod_{j=1}^{n}\left(\bar{X}_{i j}\right)^{w_{j}}, \lambda=0, \ldots, 1
$$

The value of $\lambda$ (coefficient value or threshold value of the WASPAS model) is determined using Equation (31):

$$
\lambda=\frac{\sum_{i=1}^{m} Q_{i}^{(2)}}{\sum_{i=1}^{m} Q_{i}^{(1)}+\sum_{i=1}^{m} Q_{i}^{(2)}}
$$

\section{Results Analysis}

\subsection{A Case Study in Vietnam}

With 3,000 kilometers of coastline and winds ranging from 5.5 to 7.3 meters per second, Vietnam has an exceptional natural wind potential (not accounting for seasonal variability). Offshore, the best chance for large-scale wind power generation exists. According to the World Bank, Vietnam's offshore wind potential could be as high as $500 \mathrm{GW}$. Figure 4 depicts the map of the potential of offshore wind power in Vietnam ${ }^{52}$. 


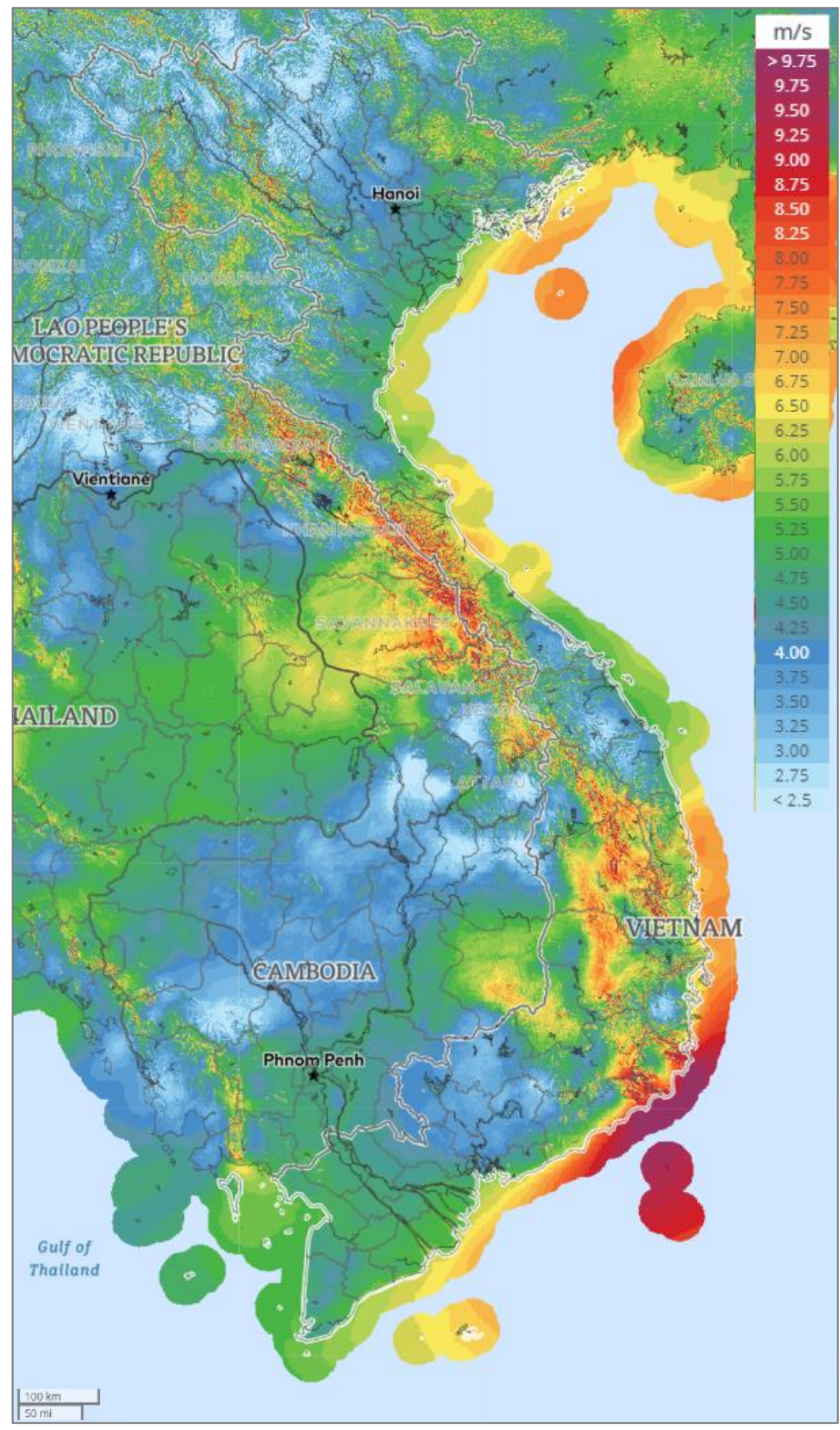

Figure 4. Map of the potential of offshore wind power in Vietnam.

In this section, the proposed aggregated framework is executed to identify the most suitable OWPS construction locations. After discussions between experts, six locations were selected as potential alternatives: Ba Ria - Vung Tau, Ben Tre, Binh Dinh, Binh Thuan, Ca Mau, Ninh Thuan, and Soc Trang (Table 4). In addition to reviewing the literature for this evaluation, the criteria system and evaluated alternatives were also determined after consultation with experts through interactive discussions. The appraisements were applied to the 15 most eligible and reliable experts (at least ten years of professional experience in energy-related fields) to increase the objectivity of the results as much as possible. Furthermore, they have made significant contributions to Vietnam's advocacy of renewable energy development policies. Six assessment dimensions and 15 evaluation criteria were identified after a literature review and expert interviews, as shown in Table 5. 
Table 4. List of potential offshore wind locations in Vietnam.

\begin{tabular}{cccc}
\hline DMU & Location & Wind Speed $(\mathbf{m} / \mathbf{s})$ & Wind Density $\left(\boldsymbol{W} / \boldsymbol{m}^{\mathbf{2}}\right)$ \\
\hline OWPS-01 & Ba Ria - Vung Tau & 6.33 & 235 \\
OWPS-02 & Ben Tre & 6.24 & 225 \\
OWPS-03 & Binh Dinh & 7.87 & 627 \\
OWPS-04 & Binh Thuan & 8.18 & 673 \\
OWPS-05 & Ca Mau & 5.94 & 196 \\
OWPS-06 & Ninh Thuan & 9.30 & 935 \\
OWPS-07 & Soc Trang & 6.25 & 216 \\
\hline
\end{tabular}

Table 5. The criteria used in the paper and their definition.

$\begin{array}{lcc}\text { Dimensions } & \text { Criteria } & \text { Definition }\end{array}$

C11. Wind speed and its distribution status
Based on the average annual wind force, the wind and monsoon conditions in places where wind farms are constructed. The wind speed computation would be based on long-term representative wind speed fluctuations in the area and investigated on site.
C12. Effective wind hours

Refers to accumulative hours of practical usage of wind power per year

\section{C2. Environmental impact}

(h).

The distance between OWPS and marine life migration determines the degree of coordination with sea area planning for marine life. Depending on the geographical context, the generator machine's selection and installation would disrupt the original seabed during construction. At the same time, the turbine would generate noise pollution throughout its rotation, resulting in low-frequency sound waves that would be harmful to marine species engaged in predation or migratory behaviors.

C22. Nautical environmen- The potential for OWPS to degrade the quality of the marine ecology tal influence and biodiversity.

C31. Seawater depth

C32. Undersea geological conditions

C3. Construction and maintenance conditions
The suitability of OWPS building also takes into account the depth of the sea, the distance from the coast, and the width of the shore.
C33. Marine conditions
This criterion assesses regional geological conditions and construction stability based on acquired data and geological prospecting.

Characteristics of the sea area like waves, tidal current, temperature, storm surge, sea ice, sea bed movement, and erosion must be considered when evaluating the hazard of complex hydrological conditions on project safety. 
C41. Employment

C4. Societal impact
The related manufacturing and service industries would grow with the project's development, and various possible job incentives would surface one after another when determining a construction location for OWPS.

As a result, it is required to use employment to assess the impact, such as which station sites affect salary, relevant industries, etc. Knowing the position of the staff, the work environment, and other factors might have an impact on employment.
C42. Policy planning
The central government's and local governments' support and promote wind farm construction; this criterion also considers if necessary legislation and policies have been implemented to encourage offshore wind projects.

\begin{abstract}
power load center
C51. Distance from the C5. Conditions on-
shore
C52. Electrical transmis- sion and distribution sys- tem

The distance between the area and the electrical load center is the distance over which electricity is transmitted from the power station to the shore (submarine cable).

The electrical system's capacity to meet future power supply requirements (e.g., substation, electrical grid).

C53. Traffic condition

C61. Cost-to-benefit ratio

C62. Construction, operation, and maintenance

tion, and main
costs

Examines the ease with which huge equipment can be transported along the shore (e.g., highway, railway, bridge, airport, dock).

C6. Economic impact

Typically, the offshore wind power profit and loss balance is utilized in estimations.

C63. Provincial financial
subsidies Relates to the subsidies promoted by the local government finance

C63. Provincial financial
subsidies Relates to the subsidies promoted by the local government finance

This criterion shows the total cost of the OWPS projects, from conception to completion and delivery in its final form, and all operating and maintenance expenditures in the surrounding area after the offshore wind farm is fully operational.

\subsection{Results of the SF-AHP Model}

In this stage, an example of the following calculation of the six main criteria presents the SFAHP procedure: wind resources $(\mathrm{C} 1)$, environmental impact $(\mathrm{C} 2)$, construction and maintenance conditions (C3), societal impact (C4), onshore conditions (C5), and economic impact (C6). The same procedures were applied to calculate the relative importance of the potential wind locations concerning the predetermined 15 criteria. A panel of 15 experts with more than ten years of working experience in the renewable energy industry was consulted by interviews to evaluate the effect of criteria on wind offshore plants' evaluation and selection process. Next, the pairwise comparison matrix using linguistic terms, the nonfuzzy comparison matrix, and the normalized comparison matrix of the SF-AHP model are presented in Tables 6-8. The consistency verification of the pairwise comparison matrices was computed as follows:
\end{abstract}

$$
\begin{gathered}
C_{12}=\frac{S I_{C_{12}}}{S U M_{C_{2}}}=\frac{4.189}{17.355}=0.241 \\
M E A N_{C_{1}}=\frac{0.145+0.241+0.215+0.115+0.318+0.164}{6}=0.199
\end{gathered}
$$




$W S V=\left[\begin{array}{llllll}1.000 & 4.189 & 3.538 & 0.226 & 6.215 & 1.261 \\ 0.239 & 1.000 & 0.894 & 0.150 & 2.371 & 0.254 \\ 0.283 & 1.119 & 1.000 & 0.156 & 2.292 & 0.240 \\ 4.433 & 6.687 & 6.430 & 1.000 & 4.534 & 4.639 \\ 0.161 & 0.422 & 0.436 & 0.221 & 1.000 & 0.316 \\ 0.793 & 3.938 & 4.167 & 0.216 & 3.162 & 1.000\end{array}\right] \times\left[\begin{array}{l}0.199 \\ 0.063 \\ 0.066 \\ 0.460 \\ 0.046 \\ 0.166\end{array}\right]=\left[\begin{array}{c}1.296 \\ 0.390 \\ 0.410 \\ 3.166 \\ 0.287 \\ 1.090\end{array}\right]$

$$
C V=\left[\begin{array}{l}
1.296 \\
0.390 \\
0.410 \\
3.166 \\
0.287 \\
1.090
\end{array}\right] /\left[\begin{array}{l}
0.199 \\
0.063 \\
0.066 \\
0.460 \\
0.046 \\
0.166
\end{array}\right]=\left[\begin{array}{l}
6.496 \\
6.212 \\
6.251 \\
6.883 \\
6.197 \\
6.571
\end{array}\right]
$$

With the six main criteria $(n=6)$, the largest eigenvector $\left(\lambda_{\max }\right)$ was calculated to identify the consistency index $(C I)$, the random index $(R I)$, and consistency ratio $(C R)$ as follows:

$$
\begin{gathered}
\lambda_{\text {max }}=\frac{6.496+6.212+6.251+6.883+6.197+6.571}{6}=6.435 \\
C I=\frac{\lambda_{\max }-n}{n-1}=\frac{6.435-6}{6-1}=0.087
\end{gathered}
$$

where $n=6, R I=1.24$, and the $C R$ value is calculated as follows:

$$
C R=\frac{C I}{R I}=\frac{0.087}{1.24}=0.070
$$

As shown in $C R=0.070<0.1$, the pairwise comparison matrix was consistent, and the result was satisfactory.

Table 6. The pairwise comparison matrix of the SF-AHP model.

\begin{tabular}{ccccccccccc}
\hline \multirow{2}{*}{ Criteria } & \multicolumn{9}{c}{ Left Criteria Is Greater } & \multicolumn{5}{c}{ Right Criteria Is Greater } & \multirow{2}{*}{ Criteria } \\
\cline { 2 - 7 } & AMI & VHI & HI & SMI & EI & SLI & LI & VLI & ALI & \\
C1 & & 6 & 2 & 6 & 1 & & & & & C2 \\
C1 & & 5 & 3 & 4 & 3 & & & & & C3 \\
C1 & & & & & & 6 & 6 & 2 & 1 & C4 \\
C1 & 5 & 4 & 4 & 2 & & & & & & C5 \\
C1 & & 1 & 3 & 2 & 4 & 5 & & & & C6 \\
C2 & & & 1 & 3 & 5 & 6 & & & & C3 \\
C2 & & & & & & 1 & 4 & 4 & 6 & C4 \\
C2 & & & 6 & 4 & 4 & 1 & & & & C5 \\
C2 & & & & & 2 & 4 & 4 & 5 & & C6 \\
C3 & & & & & & 1 & 5 & 4 & 5 & C4 \\
C3 & & & 5 & 5 & 4 & 1 & & & & C5 \\
C3 & & & & & 2 & 3 & 4 & 6 & & C6 \\
C4 & 1 & 3 & 5 & 6 & & & & & & C5 \\
C4 & & 6 & 5 & 3 & 1 & & & & & C6 \\
C5 & & & & 1 & 3 & 2 & 4 & 5 & & C6 \\
\hline
\end{tabular}

Table 7. The nonfuzzy comparison matrix of the SF-AHP model.

\begin{tabular}{ccccccc}
\hline Criteria & C1 & C2 & C3 & C4 & C5 & C6 \\
\hline C1 & 1.000 & 4.189 & 3.538 & 0.226 & 6.215 & 1.261 \\
C2 & 0.239 & 1.000 & 0.894 & 0.150 & 2.371 & 0.254 \\
C3 & 0.283 & 1.119 & 1.000 & 0.156 & 2.292 & 0.240 \\
C4 & 4.433 & 6.687 & 6.430 & 1.000 & 4.534 & 4.639 \\
C5 & 0.161 & 0.422 & 0.436 & 0.221 & 1.000 & 0.316 \\
C6 & 0.793 & 3.938 & 4.167 & 0.216 & 3.162 & 1.000 \\
\hline
\end{tabular}




\begin{tabular}{|c|c|c|c|c|c|c|c|c|c|}
\hline SUM & & & 17.355 & \multicolumn{2}{|c|}{16.465} & 1.967 & \multicolumn{2}{|c|}{19.574} & 710 \\
\hline Criteria & C1 & $\mathrm{C} 2$ & C3 & C4 & C5 & C6 & MEAN & WSV & CV \\
\hline $\mathrm{C} 1$ & 0.145 & 0.241 & 0.215 & 0.115 & 0.318 & 0.164 & 0.199 & 1.296 & 6.496 \\
\hline $\mathrm{C} 2$ & 0.035 & 0.058 & 0.054 & 0.076 & 0.121 & 0.033 & 0.063 & 0.390 & 6.212 \\
\hline $\mathrm{C} 3$ & 0.041 & 0.064 & 0.061 & 0.079 & 0.117 & 0.031 & 0.066 & 0.410 & 6.251 \\
\hline $\mathrm{C} 4$ & 0.642 & 0.385 & 0.391 & 0.508 & 0.232 & 0.602 & 0.460 & 3.166 & 6.883 \\
\hline $\mathrm{C} 5$ & 0.023 & 0.024 & 0.026 & 0.112 & 0.051 & 0.041 & 0.046 & 0.287 & 6.197 \\
\hline C6 & 0.115 & 0.227 & 0.253 & 0.110 & 0.162 & 0.130 & 0.166 & 1.090 & 6.571 \\
\hline
\end{tabular}

Following that, the integrated spherical fuzzy comparison matrix is calculated in Table 9. Then, the obtained spherical fuzzy weights of each criterion were calculated and are shown in Table 10. For explanation, the following calculation was presented for the spherical fuzzy weights of criteria $\mathrm{C} 1$ with $(\mu, v, \pi)=(0.610,0.388,0.274)$, as follows:

$$
\begin{aligned}
& \mu_{C 1}=\left[1-\prod_{i=1}^{n}\left(1-\mu_{A_{S i}}^{2}\right)^{w_{i}}\right]^{1 / 2} \\
& =\left[1-\left(1-0.500^{2}\right)^{\frac{1}{6}} *\left(1-0.679^{2}\right)^{\frac{1}{6}} *\left(1-0.657^{2}\right)^{\frac{1}{6}} *\left(1-0.296^{2}\right)^{\frac{1}{6}} *\left(1-0.773^{2}\right)^{\frac{1}{6}}\right. \\
& \left.*\left(1-0.525^{2}\right)^{\frac{1}{6}}\right]^{1 / 2}=0.610 \\
& v_{C 1}=\prod_{i=1}^{n} v_{A_{S i}}^{w_{i}}=0.400^{\frac{1}{6}} * 0.323^{\frac{1}{6}} * 0.328^{\frac{1}{6}} * 0.708^{\frac{1}{6}} * 0.246^{\frac{1}{6}} * 0.462^{\frac{1}{6}}=0.388 \\
& \pi_{C 1}=\left[\prod_{i=1}^{n}\left(1-\mu_{A_{S i}}^{2}\right)^{w_{i}}-\prod_{i=1}^{n}\left(1-\mu_{A_{S i}}^{2}-\pi_{A_{S i}}^{2}\right)^{w_{i}}\right]^{1 / 2} \\
& =\left[\left(1-0.500^{2}\right)^{\frac{1}{6}} *\left(1-0.679^{2}\right)^{\frac{1}{6}} *\left(1-0.657^{2}\right)^{\frac{1}{6}} *\left(1-0.296^{2}\right)^{\frac{1}{6}} *\left(1-0.773^{2}\right)^{\frac{1}{6}} *\left(1-0.525^{2}\right)^{\frac{1}{6}}\right. \\
& -\left(1-0.500^{2}-0.400^{2}\right)^{\frac{1}{6}} *\left(1-0.679^{2}-0.245^{2}\right)^{\frac{1}{6}} \\
& *\left(1-0.657^{2}-0.270^{2}\right)^{\frac{1}{6}} *\left(1-0.296^{2}-0.215^{2}\right)^{\frac{1}{6}} *\left(1-0.773^{2}-0.166^{2}\right)^{\frac{1}{6}} \\
& \left.*\left(1-0.525^{2}-0.312^{2}\right)^{\frac{1}{6}}\right]^{1 / 2}=0.274 \\
& S\left(\widetilde{w}_{C 1}^{S}\right)=\sqrt{\left|100 *\left[\left(3 \mu_{\bar{A}_{S}}-\frac{\pi_{\bar{A}_{S}}}{2}\right)^{2}-\left(\frac{v_{\bar{A}_{S}}}{2}-\pi_{\bar{A}_{S}}\right)^{2}\right]\right|}=\sqrt{\left|100 *\left[\left(3 * 0.610-\frac{0.274}{2}\right)^{2}-\left(\frac{0.388}{2}-0.274\right)^{2}\right]\right|} \\
& =16.915 \\
& \bar{w}_{C 1}^{S}=\frac{S\left(\widetilde{w}_{j}^{s}\right)}{\sum_{\mathrm{j}=1}^{n} S\left(\widetilde{w}_{j}^{s}\right)}=\frac{16.915}{16.915+12.268+11.124+20.039+9.259+15.072}=0.200
\end{aligned}
$$

The SF-AHP weights of the six main criteria consist of three parameters: the membership degree $(\mu)$, nonmembership degree $(v)$, and hesitancy degree $(\pi)$ of the element $x \in X$. The crisp weights of the six main criteria were calculated based on the abovementioned calculation. The criteria of societal impact (C4) with a value of 0.237 , wind resources (C1) with a value of 0.200 , and economic impact (C6) with a value of 0.178 are determined to be the most critical criteria in the stage of the SF-AHP model. Consequently, the same steps are applied to calculate the significance level of other criteria of the first stage of the paper. The integrated spherical fuzzy comparison matrix of all criteria is presented in Table A1 (Appendix A).

Table 9. The integrated spherical fuzzy comparison matrix. 


\begin{tabular}{|c|c|c|c|c|c|c|c|c|c|c|c|c|c|c|c|c|c|c|}
\hline & & C1 & & & $\mathrm{C} 2$ & & & C3 & & & $\mathrm{C} 4$ & & & C5 & & & C6 & \\
\hline & $\boldsymbol{\mu}$ & $v$ & $\pi$ & $\boldsymbol{\mu}$ & $v$ & $\pi$ & $\mu$ & $v$ & $\pi$ & $\boldsymbol{\mu}$ & $v$ & $\pi$ & $\mu$ & $v$ & $\pi$ & $\boldsymbol{\mu}$ & $v$ & $\pi$ \\
\hline $\mathrm{C} 1$ & 0.500 & 0.400 & 0.400 & 0.679 & 0.323 & 0.245 & 0.657 & 0.328 & 0.270 & 0.296 & 0.708 & 0.215 & 0.773 & 0.246 & 0.166 & 0.525 & 0.462 & 0.312 \\
\hline $\mathrm{C} 2$ & 0.292 & 0.708 & 0.217 & 0.500 & 0.400 & 0.400 & 0.485 & 0.492 & 0.331 & 0.485 & 0.492 & 0.331 & 0.592 & 0.385 & 0.304 & 0.303 & 0.696 & 0.221 \\
\hline $\mathrm{C} 3$ & 0.300 & 0.692 & 0.237 & 0.461 & 0.509 & 0.332 & 0.500 & 0.400 & 0.400 & 0.190 & 0.813 & 0.122 & 0.586 & 0.391 & 0.309 & 0.289 & 0.710 & 0.208 \\
\hline $\mathrm{C} 4$ & 0.681 & 0.328 & 0.236 & 0.794 & 0.224 & 0.145 & 0.781 & 0.236 & 0.154 & 0.500 & 0.400 & 0.400 & 0.687 & 0.323 & 0.233 & 0.700 & 0.300 & 0.222 \\
\hline C5 & 0.194 & 0.810 & 0.129 & 0.366 & 0.616 & 0.289 & 0.373 & 0.608 & 0.296 & 0.288 & 0.716 & 0.209 & 0.500 & 0.400 & 0.400 & 0.316 & 0.682 & 0.227 \\
\hline C6 & 0.413 & 0.572 & 0.297 & 0.652 & 0.341 & 0.257 & 0.665 & 0.329 & 0.247 & 0.275 & 0.724 & 0.197 & 0.618 & 0.372 & 0.270 & 0.500 & 0.400 & 0.400 \\
\hline
\end{tabular}

Table 10. The spherical weights from the SF-AHP model.

\begin{tabular}{cccccc}
\hline & \multicolumn{3}{c}{ SF-AHP Weights } & & \multicolumn{2}{c}{ Calculations to Obtain Crisp Weights } & Crisp Weights \\
\hline & $\boldsymbol{\mu}$ & $\boldsymbol{v}$ & $\boldsymbol{\pi}$ & $\boldsymbol{S}\left(\widetilde{\boldsymbol{w}}_{\boldsymbol{j}}^{\boldsymbol{s}}\right)$ & 0.200 \\
\hline $\mathrm{C} 1$ & 0.610 & 0.388 & 0.274 & 16.915 & 0.145 \\
$\mathrm{C} 2$ & 0.462 & 0.514 & 0.315 & 12.268 & 0.131 \\
$\mathrm{C} 3$ & 0.420 & 0.563 & 0.296 & 11.124 & 0.237 \\
$\mathrm{C} 4$ & 0.707 & 0.296 & 0.232 & 20.039 & 0.109 \\
$\mathrm{C} 5$ & 0.356 & 0.624 & 0.282 & 9.259 & 0.178 \\
$\mathrm{C6}$ & 0.551 & 0.437 & 0.288 & 15.072 & \\
\hline
\end{tabular}

Table 11 displays the spherical fuzzy weights and crisp weights of the SF-AHP model. The geometrical mean, defuzzification, and normalization procedures are used to calculate the influence level of each criterion. For example, the spherical fuzzy weights of the criteria wind speed and its distribution status $(\mathrm{C} 11)$ have a membership degree $(\mu)$ at 0.506 , nonmembership degree $(v)$ at 0.473 , and hesitancy degree $(\pi)$ at 0.311 . Similar to the procedure, the spherical fuzzy weights of the criteria effective wind hours $(\mathrm{C} 12)$ have membership degrees $(\mu)$, nonmembership degrees $(v)$, and hesitancy degrees $(\pi)$ of $0.447,0.538$, and 0.310 , respectively. The significance level of the criteria of the SF-AHP model is shown in Figure 5. The results show that the five most significant criteria for determining the offshore wind power station are policy planning (C42); construction, operation, and maintenance costs (C62); employment (C41), marine conditions (C33), and wind speed and its distribution status (C11), with significance levels of $7.49 \%, 7.46 \%, 7.36 \%, 7.31$, and $7.11 \%$, respectively. Meanwhile, provincial financial subsidies (C63) are specified as the least significant criterion, with a value of $7.70 \%$. The findings suggest that decision-makers should pay more attention to "C42", "C62", "C41", "C33", and "C11" than other criteria.

Table 11. Spherical fuzzy weights and crisp weights of the SF-AHP model.

\begin{tabular}{ccccccccc}
\hline Criteria & \multicolumn{3}{c}{ Geometric Mean } & \multicolumn{3}{c}{ Spherical Fuzzy Weights } \\
\cline { 2 - 6 } Crisp Weights \\
\cline { 2 - 6 } C11. Wind speed and its distribution status & $\boldsymbol{\mu}$ & $\boldsymbol{v}$ & $\boldsymbol{\pi}$ & $\boldsymbol{\mu}$ & $\boldsymbol{v}$ & $\boldsymbol{\pi}$ & 0.071 \\
C12. Effective wind hours & 0.744 & 0.473 & 0.097 & 0.506 & 0.473 & 0.311 & 0.310 & 0.062 \\
C21. Nautical life coordination & 0.800 & 0.538 & 0.096 & 0.447 & 0.538 & 0.310 \\
C22. Nautical environmental influence & 0.740 & 0.473 & 0.115 & 0.510 & 0.473 & 0.339 & 0.071 \\
C31. Seawater depth & 0.819 & 0.566 & 0.092 & 0.425 & 0.566 & 0.303 & 0.059 \\
C32. Undersea geological conditions & 0.797 & 0.535 & 0.097 & 0.451 & 0.535 & 0.311 & 0.062 \\
C33. Marine conditions & 0.756 & 0.496 & 0.102 & 0.494 & 0.496 & 0.320 & 0.069 \\
C41. Employment & 0.723 & 0.457 & 0.122 & 0.526 & 0.457 & 0.350 & 0.073 \\
C42. Policy planning & 0.720 & 0.451 & 0.119 & 0.529 & 0.451 & 0.345 & 0.074 \\
C51. Distance from the power load center & 0.717 & 0.451 & 0.104 & 0.532 & 0.451 & 0.322 & 0.075 \\
C52. Electrical transmission and distribution system & 0.812 & 0.563 & 0.083 & 0.433 & 0.563 & 0.289 & 0.060 \\
C53. Traffic condition & 0.791 & 0.533 & 0.093 & 0.457 & 0.533 & 0.305 & 0.064 \\
C61. Cost-to-benefit ratio & 0.743 & 0.468 & 0.108 & 0.507 & 0.468 & 0.328 & 0.071 \\
C63. Provincial financial subsidies & 0.719 & 0.457 & 0.101 & 0.530 & 0.457 & 0.318 & 0.075 \\
\hline
\end{tabular}


C63. Provincial financial subsidies

C53. Traffic condition

C22. Nautical environmental influence

C51. Distance from the power load center

C12. Effective wind hours

C31. Seawater depth

C52. Electrical transmission and distribution system

C32. Undersea geological conditions

C61. Cost-to-benefit ratio

C21. Nautical life coordination

C11. Wind speed and its distribution status

C33. Marine conditions

C41. Employment

C62. Construction, operation, and maintenance costs

C42. Policy planning
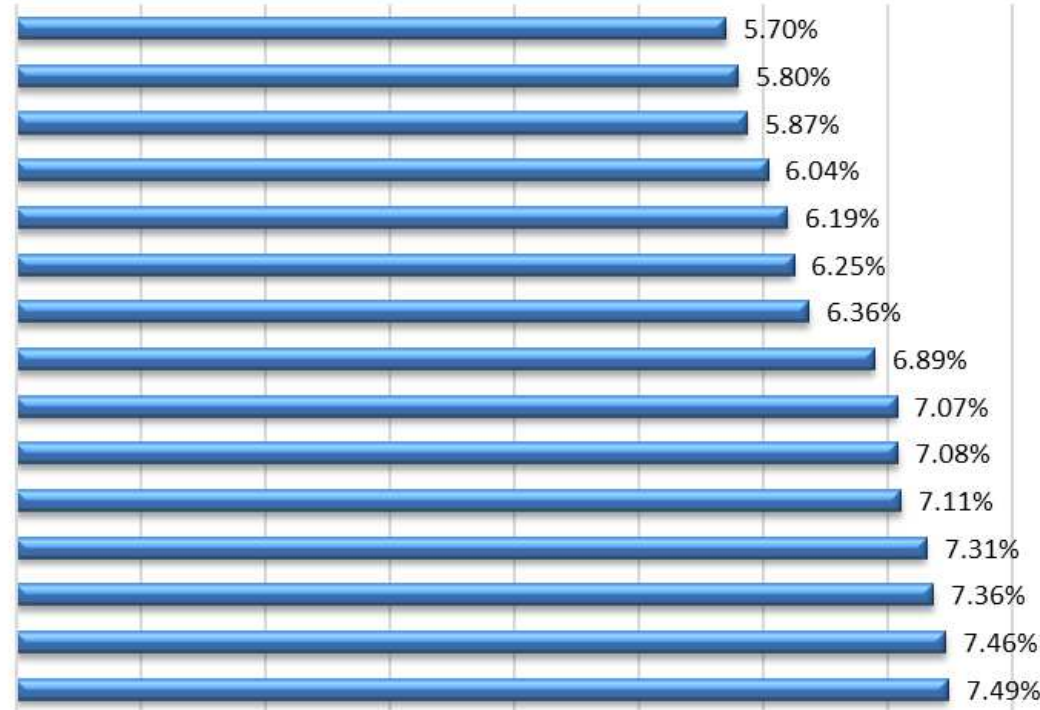

$\begin{array}{lllllllll}0 \% & 1 \% & 2 \% & 3 \% & 4 \% & 5 \% & 6 \% & 7 \% & 8 \%\end{array}$

Significant level

Figure 5. The influence level of criteria of the SF-AHP model.

\subsection{Results of the WASPAS Model}

In the second stage, this paper deployed the SF-AHP weights to combine with the WASPAS model for ranking the potential wind plants, which are Ba Ria - Vung Tau (OWPS-01), Ben Tre (OWPS-02), Binh Dinh (OWPS-03), Binh Thuan (OWPS-04), Ca Mau (OWPS-05), Ninh Thuan (OWPS-06), and Soc Trang (OWPS-07). The decision hierarchy tree for the goal of OWPS site selection is depicted in Figure 6. 


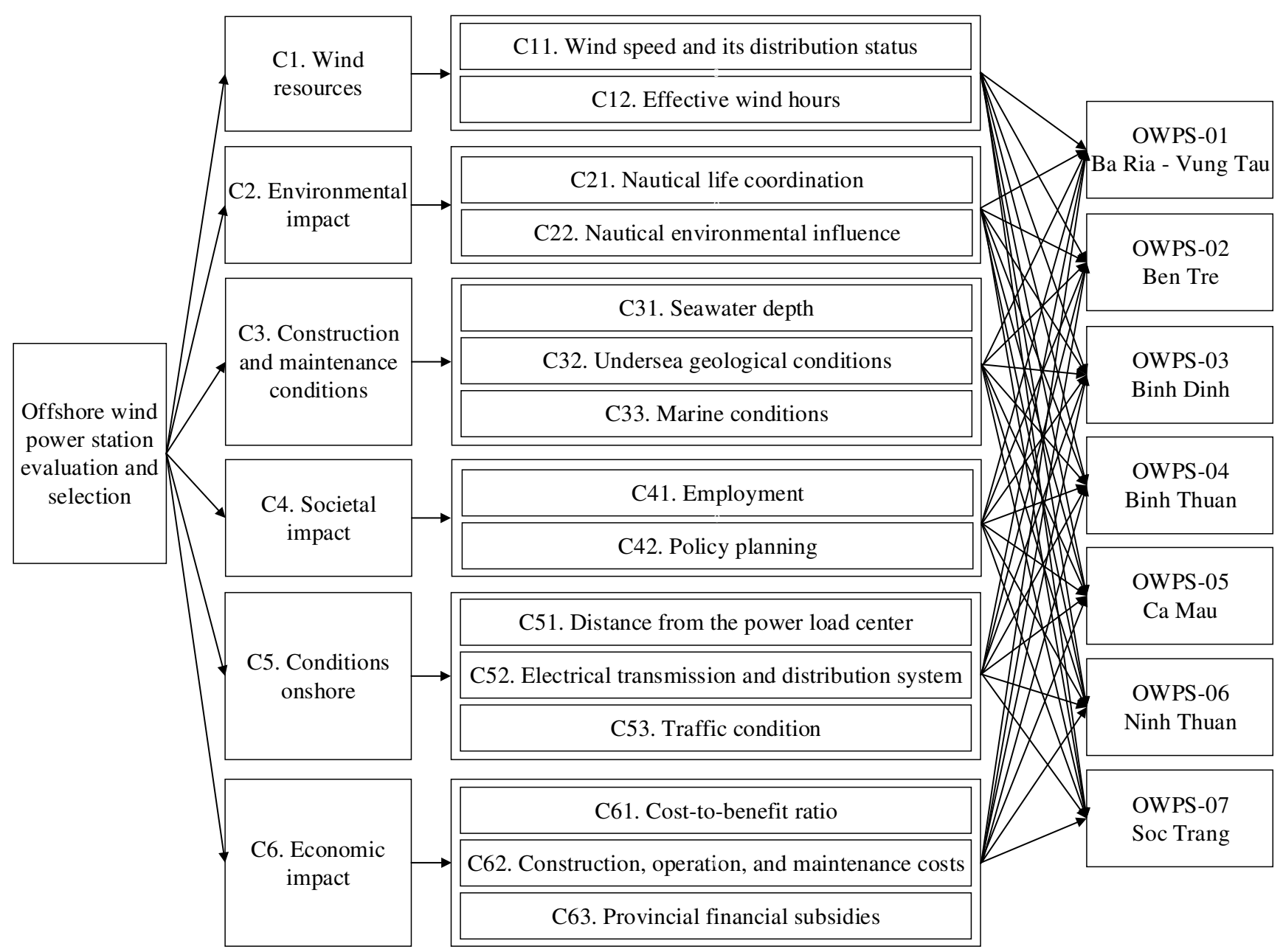

Figure 6. The decision tree of the evaluation process.

The weighted normalized matrix for the WSM and weighted normalized matrix for the WPM are displayed in Tables A2 and A3, respectively. The WASPAS model ranks the alternative based on the integrated simple additive weighting and exponentially weighted product model to obtain a compromise solution. Table 12 presents the integrated utility function $Q_{i}$ of the WASPAS model, which is calculated using the weighted sum model $Q_{i}^{(1)}$ (WSM) and the weighted product model $Q_{i}^{(2)}$ (WSM). The results show that the top three offshore wind locations are Binh Thuan (OWPS04), Ninh Thuan (OWPS-06), and Binh Dinh (OWPS-03), ranking in the first, second, and third positions with scores of $0.798,0.735$, and 0.594 , respectively. Figure 7 displays the final location ranking from the WASPAS model.

Table 12. The integrated utility function of the WASPAS model.

\begin{tabular}{cccccc}
\hline DMU & Location & $\boldsymbol{Q}_{\boldsymbol{i}}^{(\mathbf{1})}$ & $\boldsymbol{Q}_{\boldsymbol{i}}^{(\mathbf{2})}$ & $\boldsymbol{Q}_{\boldsymbol{i}}$ & Ranking \\
\hline OWPS-01 & Ba Ria - Vung Tau & 0.426 & 0.408 & 0.417 & 5 \\
OWPS-02 & Ben Tre & 0.494 & 0.474 & 0.484 & 3 \\
OWPS-03 & Binh Dinh & 0.615 & 0.572 & 0.594 & 1 \\
OWPS-04 & Binh Thuan & 0.842 & 0.754 & 0.798 & 7 \\
OWPS-05 & Ca Mau & 0.329 & 0.252 & 0.290 & 2 \\
OWPS-06 & Ninh Thuan & 0.766 & 0.704 & 0.735 & 4 \\
OWPS-07 & Soc Trang & 0.576 & 0.544 & 0.560 & \\
\hline
\end{tabular}




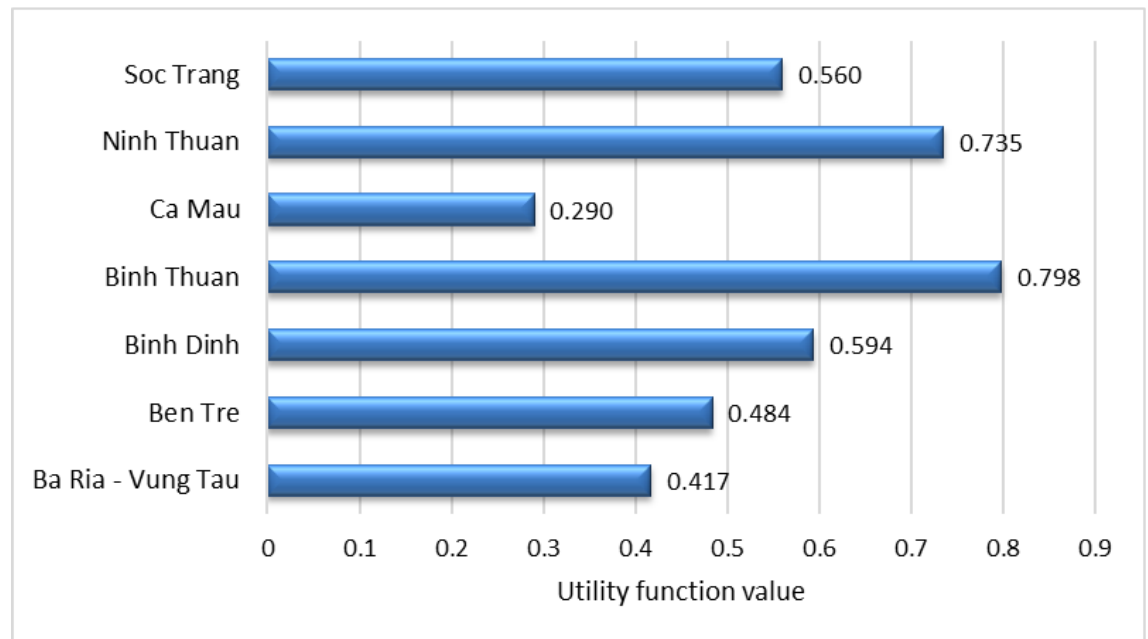

Figure 7. Location ranking of the WASPAS model.

\section{Results Validation}

To confirm the reliability and accuracy of the results and to check the robustness of the proposed approach, the following validation methods are compared with existing plant locations, sensitivity analysis, and MCDM technique comparisons.

\subsection{Comparison with the Existing Locations}

The final ranking of locations of their sustainability for OWPS construction is validated in Figure 8, which displays the provinces' total capacity of normal status OWPS projects in Vietnam as of $2021^{3}$. Most projects are now concentrated in Binh Thuan (15,800 MWp), Ninh Thuan (4,280 MWp), and Binh Dinh (2,900 MWp). Offshore wind energy can also be expanded throughout the country toward a clean energy development pathway; however, given the results, the authors recommend further analysis of these areas as they are very promising.

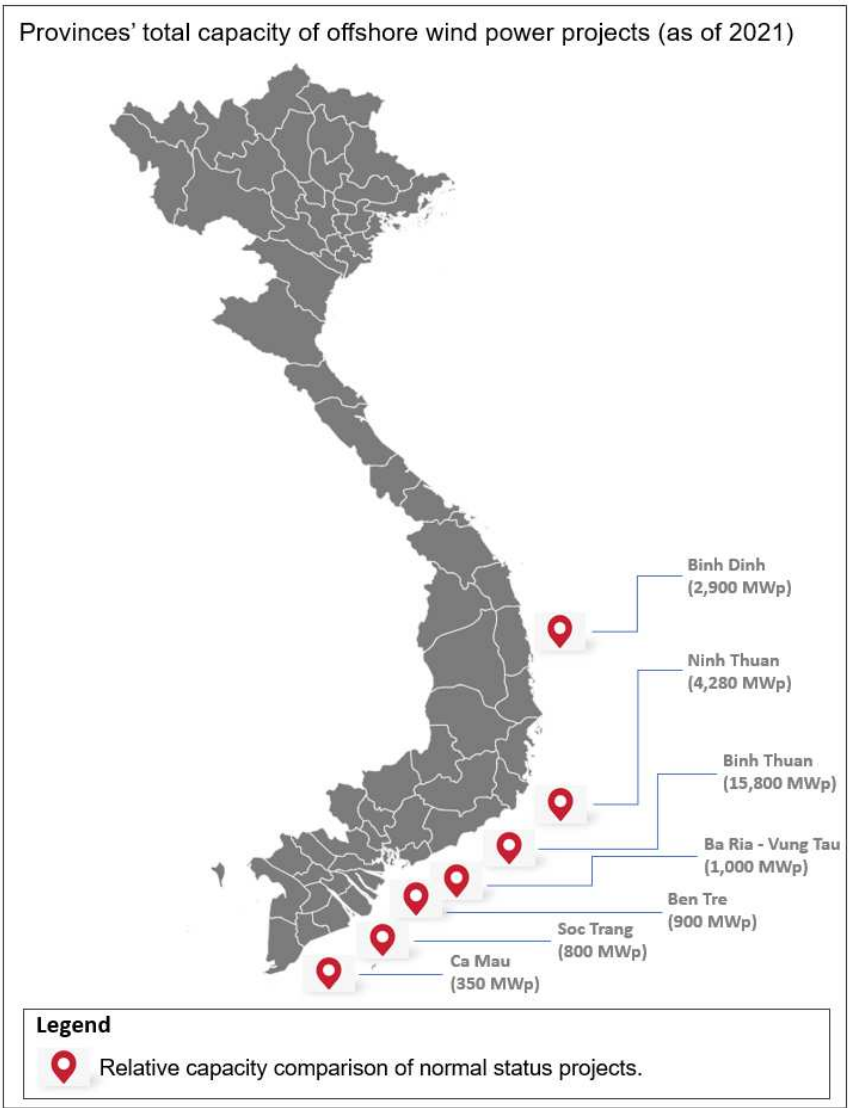

Figure 8. Map of OWPS projects in Vietnam as of 2021. 


\subsection{Sensitivity Analysis}

To demonstrate the robustness and stability of the proposed MCDM model, a sensitivity analysis is conducted for the parameters including the preference coefficient and the index weights ${ }^{53}$.

First, a sensitivity analysis of the preference coefficient (i.e., the threshold value of the WASPAS model, $\lambda$ ) is conducted to validate the ranking order ${ }^{54}$. In a previous relevant study, the value of $\lambda$ was considered to be $0.5(\lambda=0.5)$ for base case analysis. However, this setting does not reflect the actual scenario in which various decision-makers have different preferences. Hence, in this paper, the preference coefficient of the WASPAS model fluctuates in the range of $(\lambda=$ $0,0.1, \ldots, 1)$, as shown in Table 13. The change result is visualized in Figure 9. The ranking result shows that the optimal location for building the offshore wind station is always the same when changing the values of coefficient preference $(\lambda)$ from 0 to 1 . It can be concluded that Binh Thuan (OWPS-04) is consistently the optimal location to take over. Following that, Ninh Thuan (OWPS06) and Binh Dinh (OWPS-03) are also ranked second and third positions, which are also more suitable alternatives among other candidates. The reliability and correctness of the proposed model are demonstrated. Decision-maker psychology should be considered when making decisions in determining the optimal wind plant location from multiple alternatives.

Table 13. The fluctuation threshold value of the WASPAS model.

\begin{tabular}{ccccccccccccc}
\hline \multirow{2}{*}{ DMU } & \multirow{2}{*}{ Location } & \multicolumn{10}{c}{ Coefficient Values $(\boldsymbol{\lambda})$} \\
\cline { 3 - 12 } & & $\mathbf{0}$ & $\mathbf{0 . 1}$ & $\mathbf{0 . 2}$ & $\mathbf{0 . 3}$ & $\mathbf{0 . 4}$ & $\mathbf{0 . 5}$ & $\mathbf{0 . 6}$ & $\mathbf{0 . 7}$ & $\mathbf{0 . 8}$ & $\mathbf{0 . 9}$ & $\mathbf{1}$ \\
\hline OWPS-01 & Ba Ria - Vung Tau & 0.408 & 0.410 & 0.412 & 0.414 & 0.415 & 0.417 & 0.419 & 0.421 & 0.422 & 0.424 & 0.426 \\
OWPS-02 & Ben Tre & 0.474 & 0.476 & 0.478 & 0.480 & 0.482 & 0.484 & 0.486 & 0.488 & 0.490 & 0.492 & 0.494 \\
OWPS-03 & Binh Dinh & 0.572 & 0.577 & 0.581 & 0.585 & 0.590 & 0.594 & 0.598 & 0.602 & 0.607 & 0.611 & 0.615 \\
OWPS-04 & Binh Thuan & 0.754 & 0.762 & 0.771 & 0.780 & 0.789 & 0.798 & 0.806 & 0.815 & 0.824 & 0.833 & 0.842 \\
OWPS-05 & Ca Mau & 0.252 & 0.259 & 0.267 & 0.275 & 0.282 & 0.290 & 0.298 & 0.306 & 0.313 & 0.321 & 0.329 \\
OWPS-06 & Ninh Thuan & 0.704 & 0.710 & 0.717 & 0.723 & 0.729 & 0.735 & 0.741 & 0.748 & 0.754 & 0.760 & 0.766 \\
OWPS-07 & Soc Trang & 0.544 & 0.547 & 0.551 & 0.554 & 0.557 & 0.560 & 0.563 & 0.567 & 0.570 & 0.573 & 0.576 \\
\hline
\end{tabular}

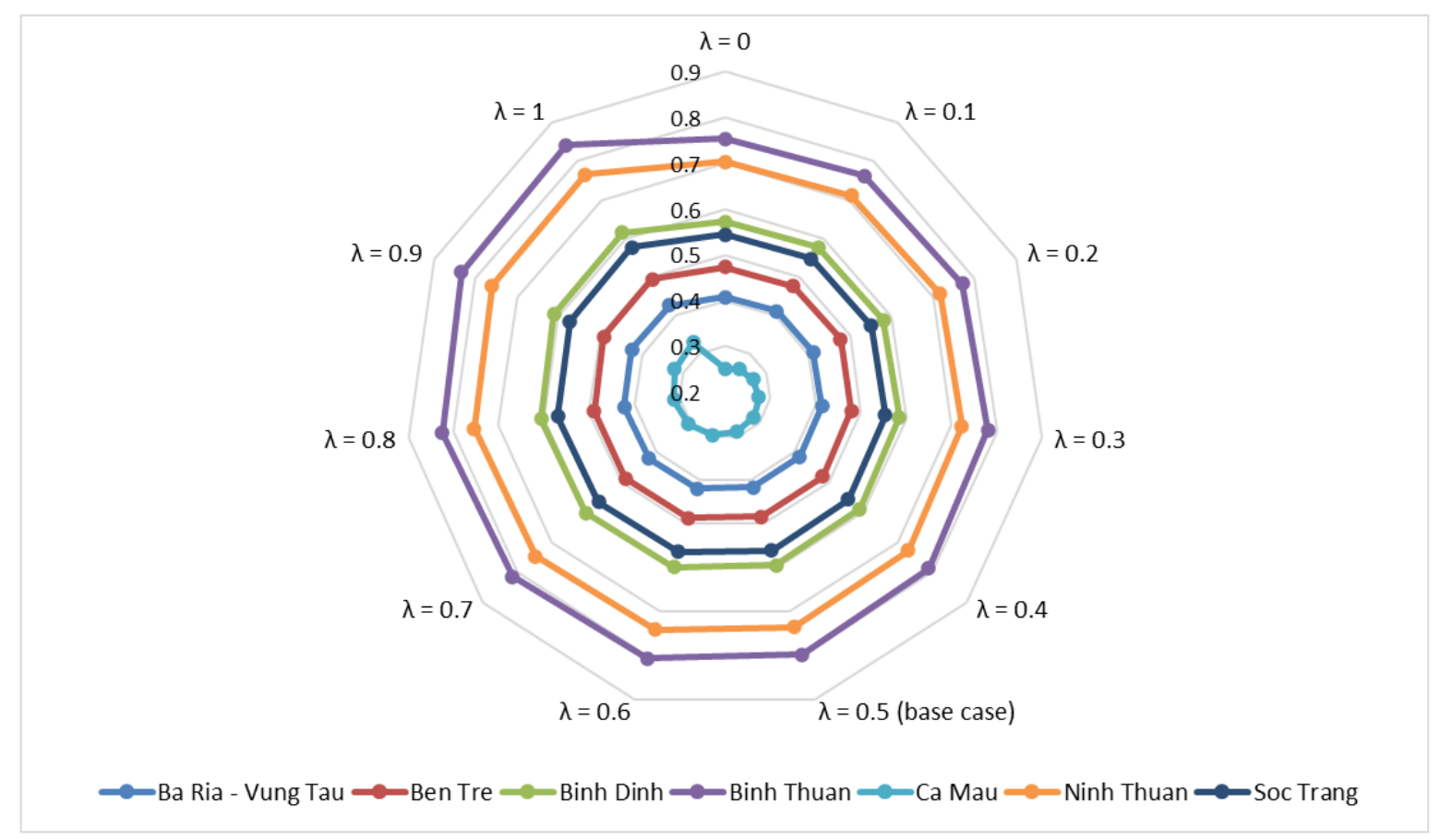

Figure 9. Sensitivity analysis of the threshold value of the WASPAS model.

Second, a sensitivity analysis of criteria is conducted to investigate the impact of criteria on the ranking of wind plant locations. The top five main criteria are selected to fluctuate their weights from $\pm 10 \%, \pm 30 \%$ and $\pm 50 \%{ }^{55}$, which are policy planning (C42); construction, operation, and maintenance costs (C62); employment (C41); marine conditions (C33); and wind speed and its distribution status (C11). In total, there will be 30 scenarios of sensitivity analysis in this case. Figure 10 depicts that the final ranking results of the seven locations are fundamentally stable. The results show that Binh Thuan (OWPS-04) and Ninh Thuan (OWPS-06) are always ranked first and 
second on $10 \%, 30 \%, 50 \%$ more weight and $10 \%, 30 \%, 50 \%$ less weight than the base case. Generally, the curve is relatively smooth, revealing that the ranking result of the proposed MCDM model of SF-AHP and WASPAS is stable and applicable.

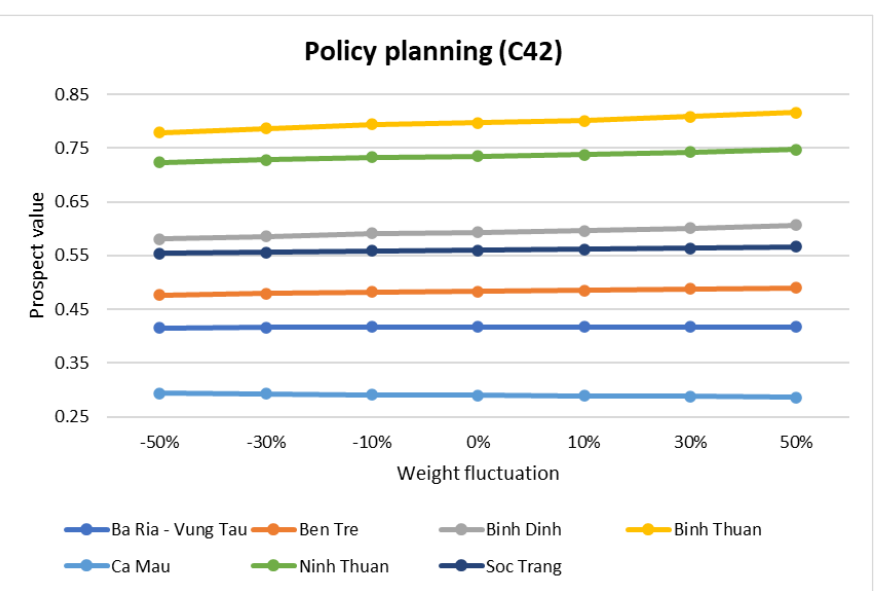

(a) Policy planning (C42).

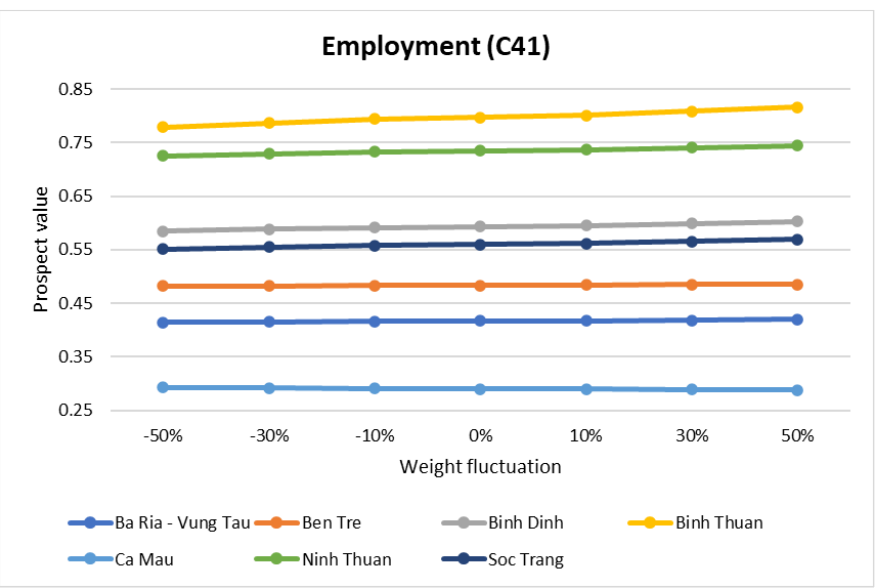

(c) Employment (C41).

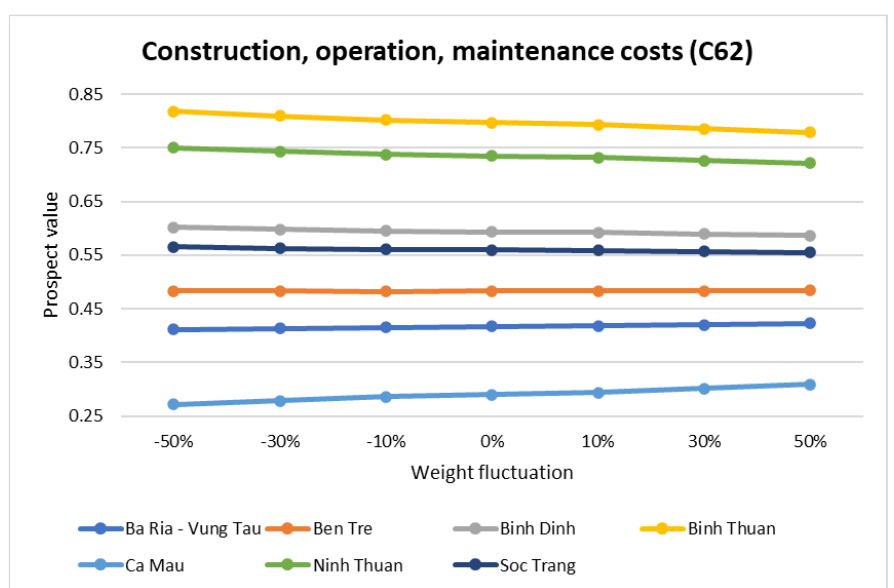

(b) Construction, operation, maintenance costs (C62).

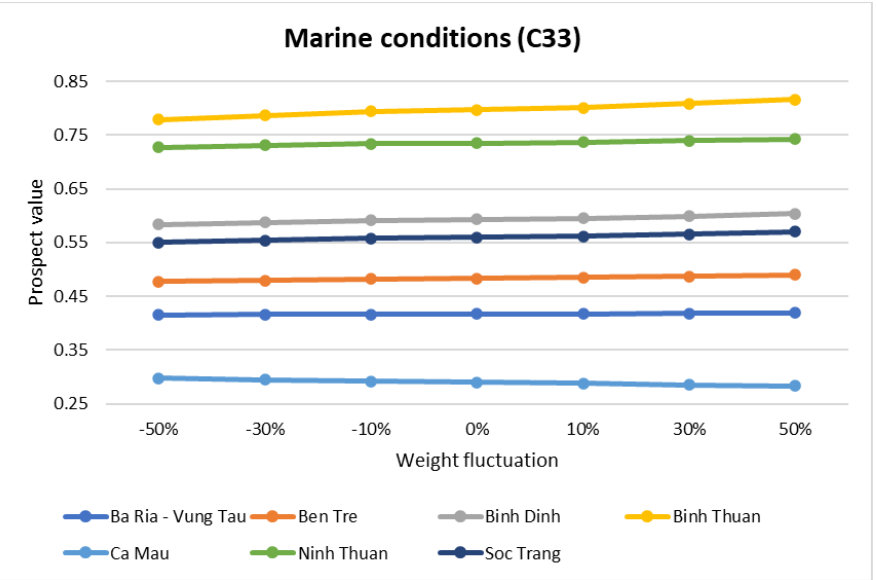

(d) Marine conditions (C33).

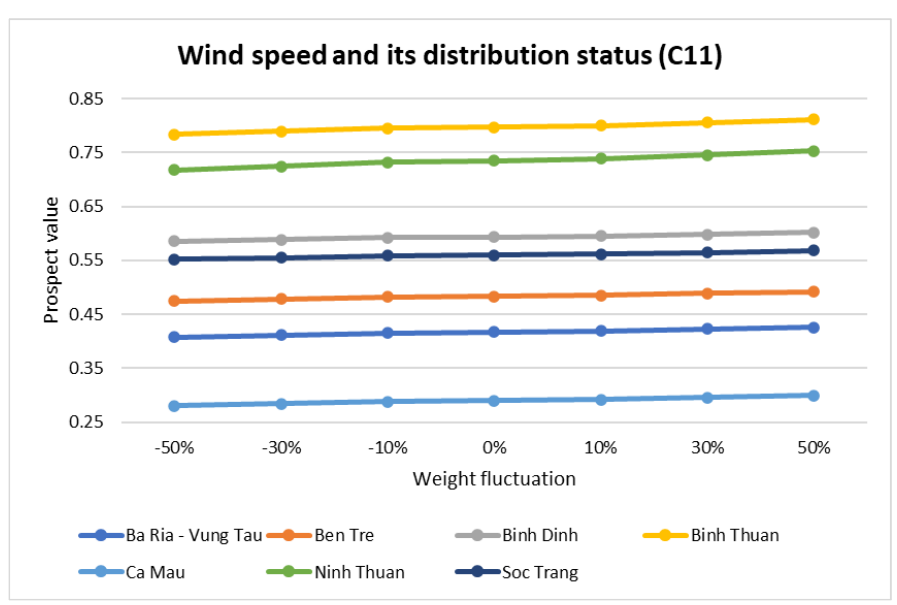

(e) Wind speed and its distribution status (C11).

Figure 10. Sensitivity analysis of the five most significant criteria.

\subsection{Comparative Analysis}

In the MCDM approach, the applicability and rationality of the proposed methods must be proven by comparison with stable and mature methods commonly used in related studies. In this paper, the ranking of wind locations using the integrated SF-AHP and WASPAS models is evaluated by comparison with the Technique for Order of Preference by Similarity to Ideal Solution (TOPSIS), Combined Compromise Solution (CoCoSo), and Evaluation Based on Distance from 
Average Solution (EDAS). The TOPSIS method is known as the classical MCDM model based on the concept that the selected alternative should have the shortest distance from the positive ideal solution and the farthest distance from the negative ideal solution ${ }^{56}$. The EDAS method could be used most effectively for solving a larger number of complex decision-making problems ${ }^{57}$. Meanwhile, the CoCoSo method has algorithm steps similar to those of the WASPAS method, which was built based on aggregated simple additive weighting and an exponentially weighted product model to obtain a compromise solution ${ }^{58}$.

The comparison of four kinds of ranking methods is shown in Table 14 and visualized in Figure 11. The comparison shows that the ranking of the offshore wind location has given the same result as the model proposed in this paper, which is among integrated models of SF-AHP and WASPAS, SF-AHP and TOPSIS, and SF-AHP and EDAS. The ranking of the SF-AHP and CoCoSo models is slightly different from that of the proposed model. The difference is between Binh Thuan (OWPS-04) and Ninh Thuan (OWPS-06). Hence, the proposed MCDM integrated model is robust, and the obtained result is reliable and can be a useful guideline for decision-makers, investors, or governments in determining the optimal offshore wind plants in Vietnam or related industries.

Table 14. The comparison of four kinds of ranking methods.

\begin{tabular}{|c|c|c|c|c|c|c|c|c|c|}
\hline \multirow[t]{2}{*}{ DMU } & \multirow[t]{2}{*}{ Location } & \multicolumn{2}{|c|}{$\begin{array}{c}\text { SF-AHP } \\
\text { WASPAS }\end{array}$} & \multicolumn{2}{|c|}{$\begin{array}{l}\text { SF-AHP } \\
\text { TOPSIS }\end{array}$} & \multicolumn{2}{|c|}{$\begin{array}{c}\text { SF-AHP } \\
\text { COCOSO }\end{array}$} & \multicolumn{2}{|c|}{$\begin{array}{c}\text { SF-AHP } \\
\text { EDAS }\end{array}$} \\
\hline & & Value & Ranking & Value & Ranking & Value & Ranking & Value & Ranking \\
\hline OWPS-01 & Ba Ria - Vung Tau & 0.417 & 6 & 0.347 & 6 & 4.240 & 6 & 0.290 & 6 \\
\hline OWPS-02 & Ben Tre & 0.484 & 5 & 0.409 & 5 & 4.764 & 5 & 0.392 & 5 \\
\hline OWPS-03 & Binh Dinh & 0.594 & 3 & 0.528 & 3 & 5.232 & 3 & 0.567 & 3 \\
\hline OWPS-04 & Binh Thuan & 0.798 & 1 & 0.681 & 1 & 5.654 & 2 & 0.919 & 1 \\
\hline OWPS-05 & $\mathrm{Ca} \mathrm{Mau}$ & 0.290 & 7 & 0.287 & 7 & 0.910 & 7 & 0.092 & 7 \\
\hline OWPS-06 & Ninh Thuan & 0.735 & 2 & 0.670 & 2 & 5.926 & 1 & 0.825 & 2 \\
\hline OWPS-07 & Soc Trang & 0.560 & 4 & 0.495 & 4 & 5.090 & 4 & 0.510 & 4 \\
\hline
\end{tabular}

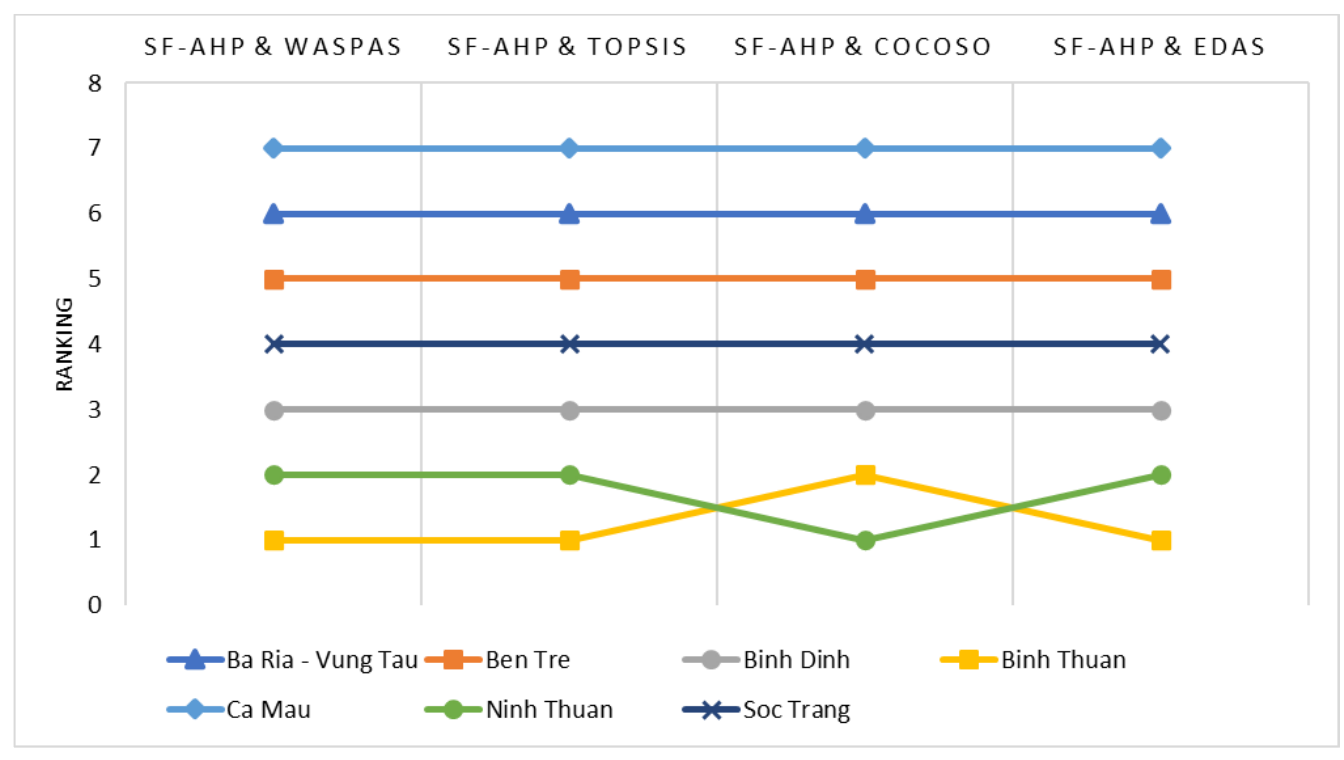

Figure 11. Ranking results of compared methods.

\section{Concluding Remarks}

The aim of decreasing global greenhouse gas emissions will depend mainly on developing economies such as Vietnam. Critically, the COVID-19 epidemic has highlighted the vulnerabilities in this fossil fuel-based economy, accelerating the transition faster than before. Pathways toward low carbon development, Vietnam is taking steps to tap into its good wind energy potentials. Selecting the appropriate locations for offshore wind plant installation is the topmost decision, which is a complicated multicriteria decision-making (MCDM) problem with the coexistence of multiple factors. There is a problem with incomplete decision information use and information loss during the decision-making process, and it is easy to overlook the interaction difficulty in a fuzzy environment. 


\begin{tabular}{|c|c|c|c|c|c|c|c|c|c|c|c|c|c|c|c|}
\hline & \multicolumn{3}{|c|}{ C11 } & \multicolumn{3}{|c|}{$\mathrm{C} 12$} & \multicolumn{3}{|c|}{$\mathrm{C} 21$} & \multicolumn{3}{|c|}{$\mathrm{C} 22$} & \multicolumn{3}{|c|}{ C31 } \\
\hline & $\mu$ & $v$ & $\pi$ & $\mu$ & $v$ & $\pi$ & $\mu$ & $v$ & $\pi$ & $\mu$ & $v$ & $\pi$ & $\mu$ & $v$ & $\pi$ \\
\hline C11 & 0.500 & 0.400 & 0.400 & 0.557 & 0.415 & 0.321 & 0.470 & 0.504 & 0.331 & 0.546 & 0.446 & 0.304 & 0.461 & 0.534 & 0.293 \\
\hline $\mathrm{C} 12$ & 0.391 & 0.584 & 0.310 & 0.500 & 0.400 & 0.400 & 0.493 & 0.482 & 0.336 & 0.424 & 0.576 & 0.275 & 0.519 & 0.476 & 0.288 \\
\hline $\mathrm{C} 21$ & 0.466 & 0.497 & 0.336 & 0.458 & 0.511 & 0.430 & 0.500 & 0.400 & 0.400 & 0.596 & 0.391 & 0.297 & 0.435 & 0.556 & 0.300 \\
\hline $\mathrm{C} 22$ & 0.402 & 0.589 & 0.289 & 0.503 & 0.490 & 0.216 & 0.331 & 0.660 & 0.262 & 0.500 & 0.400 & 0.400 & 0.390 & 0.604 & 0.280 \\
\hline C31 & 0.480 & 0.510 & 0.298 & 0.403 & 0.585 & 0.182 & 0.399 & 0.590 & 0.282 & 0.557 & 0.429 & 0.302 & 0.500 & 0.400 & 0.400 \\
\hline C32 & 0.373 & 0.613 & 0.283 & 0.442 & 0.523 & 0.234 & 0.381 & 0.603 & 0.296 & 0.445 & 0.536 & 0.314 & 0.523 & 0.455 & 0.313 \\
\hline C33 & 0.541 & 0.447 & 0.305 & 0.547 & 0.432 & 0.488 & 0.458 & 0.511 & 0.338 & 0.594 & 0.394 & 0.289 & 0.594 & 0.392 & 0.287 \\
\hline $\mathrm{C} 41$ & 0.551 & 0.430 & 0.308 & 0.578 & 0.405 & 0.471 & 0.537 & 0.439 & 0.313 & 0.582 & 0.419 & 0.276 & 0.512 & 0.492 & 0.276 \\
\hline $\mathrm{C} 42$ & 0.498 & 0.493 & 0.294 & 0.536 & 0.441 & 0.297 & 0.406 & 0.580 & 0.293 & 0.531 & 0.452 & 0.313 & 0.562 & 0.413 & 0.306 \\
\hline C51 & 0.384 & 0.607 & 0.282 & 0.512 & 0.470 & 0.179 & 0.357 & 0.635 & 0.269 & 0.485 & 0.507 & 0.294 & 0.462 & 0.512 & 0.318 \\
\hline C52 & 0.300 & 0.690 & 0.250 & 0.503 & 0.476 & 0.258 & 0.498 & 0.479 & 0.321 & 0.421 & 0.560 & 0.310 & 0.470 & 0.506 & 0.332 \\
\hline C53 & 0.381 & 0.589 & 0.316 & 0.450 & 0.543 & 0.142 & 0.331 & 0.660 & 0.262 & 0.458 & 0.511 & 0.338 & 0.361 & 0.613 & 0.302 \\
\hline C61 & 0.542 & 0.436 & 0.311 & 0.508 & 0.473 & 0.325 & 0.458 & 0.511 & 0.338 & 0.571 & 0.416 & 0.299 & 0.541 & 0.427 & 0.322 \\
\hline C62 & 0.429 & 0.554 & 0.303 & 0.517 & 0.461 & 0.407 & 0.536 & 0.441 & 0.315 & 0.634 & 0.365 & 0.261 & 0.594 & 0.394 & 0.289 \\
\hline \multirow[t]{2}{*}{ C63 } & 0.484 & 0.495 & 0.318 & 0.450 & 0.543 & 0.155 & 0.395 & 0.596 & 0.285 & 0.488 & 0.493 & 0.316 & 0.458 & 0.534 & 0.291 \\
\hline & \multicolumn{3}{|c|}{$\mathrm{C} 32$} & \multicolumn{3}{|c|}{$\mathrm{C33}$} & \multicolumn{3}{|c|}{ C41 } & \multicolumn{3}{|c|}{$\mathrm{C} 42$} & \multicolumn{3}{|c|}{ C51 } \\
\hline C11 & 0.565 & 0.421 & 0.305 & 0.398 & 0.599 & 0.280 & 0.368 & 0.628 & 0.272 & 0.441 & 0.556 & 0.286 & 0.567 & 0.424 & 0.299 \\
\hline C12 & 0.496 & 0.476 & 0.332 & 0.386 & 0.607 & 0.279 & 0.373 & 0.621 & 0.273 & 0.404 & 0.586 & 0.293 & 0.419 & 0.573 & 0.289 \\
\hline $\mathrm{C} 21$ & 0.569 & 0.412 & 0.311 & 0.493 & 0.482 & 0.336 & 0.407 & 0.582 & 0.293 & 0.529 & 0.459 & 0.304 & 0.593 & 0.397 & 0.291 \\
\hline $\mathrm{C} 22$ & 0.500 & 0.486 & 0.314 & 0.340 & 0.659 & 0.252 & 0.319 & 0.685 & 0.228 & 0.386 & 0.612 & 0.278 & 0.453 & 0.544 & 0.285 \\
\hline C31 & 0.418 & 0.571 & 0.293 & 0.346 & 0.650 & 0.253 & 0.414 & 0.592 & 0.257 & 0.378 & 0.612 & 0.279 & 0.472 & 0.511 & 0.314 \\
\hline
\end{tabular}

Author Contributions: Conceptualization, T.-T.D.; Data curation, T.-T.D.; Formal analysis, N.-A.-T.N.; Funding acquisition, C.-N.W.; Investigation, N.-A.-T.N.; Methodology, T.-T.D.; Project administration, C.N.W.; Software, T.-T.D.; Validation, C.-N.W. and N.-A.-T.N.; Writing-original draft, T.-T.D. and N.-A.-T.N.; Writing-review and editing, C.-N.W. and N.-A.-T.N. All authors have read and agreed to the published version of the manuscript.

Funding: The authors have no relevant financial or non-financial interests to disclose.

Acknowledgments: The authors appreciate the support from the National Kaohsiung University of Science and Technology, Taiwan.

Competing interests: The authors declare no competing interests.

\section{Appendix A}

Table A1. The integrated spherical fuzzy comparison matrix of the SF-AHP model. 


\begin{tabular}{|c|c|c|c|c|c|c|c|c|c|c|c|c|c|c|c|}
\hline C32 & 0.500 & 0.400 & 0.400 & 0.493 & 0.482 & 0.336 & 0.431 & 0.562 & 0.289 & 0.471 & 0.508 & 0.328 & 0.629 & 0.367 & 0.273 \\
\hline C33 & 0.458 & 0.511 & 0.338 & 0.500 & 0.400 & 0.400 & 0.493 & 0.482 & 0.336 & 0.450 & 0.531 & 0.321 & 0.585 & 0.406 & 0.295 \\
\hline $\mathrm{C} 41$ & 0.498 & 0.484 & 0.308 & 0.458 & 0.511 & 0.338 & 0.500 & 0.400 & 0.400 & 0.493 & 0.482 & 0.336 & 0.619 & 0.356 & 0.298 \\
\hline $\mathrm{C} 42$ & 0.475 & 0.494 & 0.336 & 0.493 & 0.475 & 0.332 & 0.458 & 0.511 & 0.338 & 0.500 & 0.400 & 0.400 & 0.659 & 0.342 & 0.254 \\
\hline C51 & 0.331 & 0.665 & 0.249 & 0.331 & 0.662 & 0.255 & 0.338 & 0.647 & 0.276 & 0.288 & 0.710 & 0.216 & 0.500 & 0.400 & 0.400 \\
\hline C52 & 0.432 & 0.549 & 0.310 & 0.421 & 0.560 & 0.310 & 0.384 & 0.598 & 0.296 & 0.338 & 0.649 & 0.269 & 0.536 & 0.450 & 0.307 \\
\hline C53 & 0.338 & 0.649 & 0.269 & 0.325 & 0.675 & 0.241 & 0.425 & 0.550 & 0.314 & 0.373 & 0.619 & 0.275 & 0.429 & 0.544 & 0.324 \\
\hline C61 & 0.489 & 0.491 & 0.314 & 0.466 & 0.505 & 0.329 & 0.475 & 0.494 & 0.336 & 0.446 & 0.509 & 0.352 & 0.512 & 0.464 & 0.321 \\
\hline C62 & 0.536 & 0.446 & 0.301 & 0.541 & 0.447 & 0.305 & 0.498 & 0.472 & 0.331 & 0.446 & 0.532 & 0.307 & 0.507 & 0.483 & 0.304 \\
\hline \multirow[t]{2}{*}{ C63 } & 0.347 & 0.633 & 0.283 & 0.381 & 0.605 & 0.289 & 0.399 & 0.576 & 0.316 & 0.354 & 0.636 & 0.275 & 0.391 & 0.584 & 0.310 \\
\hline & \multicolumn{3}{|c|}{ C52 } & \multicolumn{3}{|c|}{$\mathrm{C53}$} & \multicolumn{3}{|c|}{ C61 } & \multicolumn{3}{|c|}{ C62 } & \multicolumn{3}{|c|}{$\mathrm{C63}$} \\
\hline C11 & 0.641 & 0.337 & 0.287 & 0.566 & 0.397 & 0.328 & 0.396 & 0.595 & 0.286 & 0.509 & 0.479 & 0.303 & 0.460 & 0.528 & 0.311 \\
\hline $\mathrm{C} 12$ & 0.435 & 0.556 & 0.300 & 0.479 & 0.522 & 0.281 & 0.431 & 0.559 & 0.296 & 0.423 & 0.567 & 0.300 & 0.479 & 0.522 & 0.281 \\
\hline $\mathrm{C} 21$ & 0.447 & 0.541 & 0.307 & 0.596 & 0.391 & 0.297 & 0.493 & 0.482 & 0.336 & 0.404 & 0.586 & 0.293 & 0.550 & 0.443 & 0.296 \\
\hline $\mathrm{C} 22$ & 0.529 & 0.454 & 0.318 & 0.493 & 0.482 & 0.336 & 0.327 & 0.674 & 0.245 & 0.305 & 0.696 & 0.220 & 0.448 & 0.543 & 0.303 \\
\hline C31 & 0.486 & 0.497 & 0.329 & 0.576 & 0.389 & 0.324 & 0.388 & 0.599 & 0.292 & 0.340 & 0.659 & 0.252 & 0.479 & 0.518 & 0.288 \\
\hline C32 & 0.515 & 0.469 & 0.318 & 0.608 & 0.373 & 0.297 & 0.451 & 0.538 & 0.303 & 0.390 & 0.604 & 0.276 & 0.595 & 0.377 & 0.307 \\
\hline C33 & 0.529 & 0.454 & 0.318 & 0.617 & 0.385 & 0.274 & 0.476 & 0.504 & 0.324 & 0.398 & 0.599 & 0.280 & 0.559 & 0.426 & 0.309 \\
\hline $\mathrm{C} 41$ & 0.570 & 0.410 & 0.309 & 0.513 & 0.467 & 0.317 & 0.471 & 0.508 & 0.328 & 0.438 & 0.546 & 0.313 & 0.552 & 0.421 & 0.325 \\
\hline $\mathrm{C} 42$ & 0.608 & 0.373 & 0.297 & 0.572 & 0.421 & 0.297 & 0.495 & 0.468 & 0.349 & 0.480 & 0.505 & 0.303 & 0.603 & 0.383 & 0.296 \\
\hline C51 & 0.409 & 0.586 & 0.287 & 0.517 & 0.459 & 0.329 & 0.435 & 0.553 & 0.307 & 0.433 & 0.564 & 0.290 & 0.557 & 0.415 & 0.321 \\
\hline C52 & 0.500 & 0.400 & 0.400 & 0.444 & 0.531 & 0.327 & 0.441 & 0.563 & 0.264 & 0.477 & 0.515 & 0.300 & 0.571 & 0.421 & 0.291 \\
\hline C53 & 0.493 & 0.466 & 0.340 & 0.500 & 0.400 & 0.400 & 0.375 & 0.621 & 0.278 & 0.378 & 0.612 & 0.279 & 0.568 & 0.406 & 0.314 \\
\hline C61 & 0.472 & 0.527 & 0.273 & 0.545 & 0.436 & 0.313 & 0.500 & 0.400 & 0.400 & 0.493 & 0.482 & 0.336 & 0.552 & 0.421 & 0.325 \\
\hline C62 & 0.454 & 0.530 & 0.308 & 0.562 & 0.413 & 0.306 & 0.458 & 0.511 & 0.338 & 0.500 & 0.400 & 0.400 & 0.637 & 0.367 & 0.263 \\
\hline C63 & 0.377 & 0.613 & 0.278 & 0.373 & 0.605 & 0.296 & 0.399 & 0.576 & 0.316 & 0.331 & 0.669 & 0.242 & 0.500 & 0.400 & 0.400 \\
\hline
\end{tabular}

Table A2. The weighted normalized matrix for WSM of the WASPAS model.

\begin{tabular}{cccccccccc}
\hline DMU & Location & $\mathbf{C 1 1}$ & $\mathbf{C 1 2}$ & $\mathbf{C 2 1}$ & $\mathbf{C 2 2}$ & $\mathbf{C 3 1}$ & $\mathbf{C 3 2}$ & $\mathbf{C 3 3}$ & $\mathbf{C 4 1}$ \\
\hline OWPS-01 & Ba Ria - Vung Tau & 0.048 & 0.016 & 0.031 & 0.018 & 0.019 & 0.026 & 0.032 & 0.034 \\
OWPS-02 & Ben Tre & 0.048 & 0.015 & 0.040 & 0.025 & 0.031 & 0.040 & 0.044 & 0.034 \\
OWPS-03 & Binh Dinh & 0.048 & 0.014 & 0.051 & 0.036 & 0.043 & 0.052 & 0.053 & 0.051 \\
OWPS-04 & Binh Thuan & 0.063 & 0.045 & 0.048 & 0.059 & 0.062 & 0.069 & 0.073 & 0.074 \\
OWPS-05 & Ca Mau & 0.045 & 0.013 & 0.011 & 0.011 & 0.012 & 0.011 & 0.009 & 0.017 \\
OWPS-06 & Ninh Thuan & 0.071 & 0.062 & 0.071 & 0.045 & 0.048 & 0.057 & 0.050 & 0.054 \\
OWPS-07 & Soc Trang & 0.048 & 0.014 & 0.051 & 0.032 & 0.038 & 0.049 & 0.053 & 0.051 \\
\hline DMU & Location & $\mathbf{C 4 2}$ & $\mathbf{C 5 1}$ & $\mathbf{C 5 2}$ & $\mathbf{C 5 3}$ & $\mathbf{C 6 1}$ & $\mathbf{C 6 2}$ & $\mathbf{C 6 3}$ & \\
\hline OWPS-01 & Ba Ria - Vung Tau & 0.030 & 0.040 & 0.025 & 0.027 & 0.019 & 0.041 & 0.019 & \\
OWPS-02 & Ben Tre & 0.045 & 0.019 & 0.036 & 0.025 & 0.022 & 0.031 & 0.040 & \\
OWPS-03 & Binh Dinh & 0.060 & 0.014 & 0.047 & 0.033 & 0.041 & 0.022 & 0.050 & \\
OWPS-04 & Binh Thuan & 0.075 & 0.011 & 0.064 & 0.058 & 0.071 & 0.014 & 0.057 & \\
OWPS-05 & Ca Mau & 0.015 & 0.060 & 0.011 & 0.009 & 0.019 & 0.075 & 0.010 & \\
OWPS-06 & Ninh Thuan & 0.060 & 0.012 & 0.058 & 0.051 & 0.054 & 0.018 & 0.055 & \\
OWPS-07 & Soc Trang & 0.045 & 0.014 & 0.044 & 0.033 & 0.041 & 0.025 & 0.038 & \\
\hline
\end{tabular}

Table A3. Exponentially weighted normalized matrix for WPM of the WASPAS model.

\begin{tabular}{cccccccccc}
\hline DMU & Location & C11 & C12 & C21 & C22 & C31 & C32 & C33 & C41 \\
\hline OWPS-01 & Ba Ria - Vung Tau & 0.973 & 0.918 & 0.944 & 0.933 & 0.929 & 0.935 & 0.942 & 0.945 \\
\hline
\end{tabular}




\begin{tabular}{cccccccccc}
\hline OWPS-02 & Ben Tre & 0.972 & 0.916 & 0.960 & 0.951 & 0.958 & 0.964 & 0.963 & 0.945 \\
OWPS-03 & Binh Dinh & 0.972 & 0.913 & 0.977 & 0.972 & 0.977 & 0.980 & 0.976 & 0.973 \\
OWPS-04 & Binh Thuan & 0.991 & 0.980 & 0.973 & 1.000 & 1.000 & 1.000 & 1.000 & 1.000 \\
OWPS-05 & Ca Mau & 0.969 & 0.908 & 0.878 & 0.908 & 0.902 & 0.884 & 0.856 & 0.898 \\
OWPS-06 & Ninh Thuan & 1.000 & 1.000 & 1.000 & 0.985 & 0.984 & 0.988 & 0.972 & 0.977 \\
OWPS-07 & Soc Trang & 0.972 & 0.913 & 0.977 & 0.964 & 0.970 & 0.977 & 0.976 & 0.973 \\
\hline DMU & Location & $\mathbf{C 4 2}$ & $\mathbf{C 5 1}$ & $\mathbf{C 5 2}$ & $\mathbf{C 5 3}$ & $\mathbf{C 6 1}$ & $\mathbf{C 6 2}$ & $\mathbf{C 6 3}$ & \\
\hline OWPS-01 & Ba Ria - Vung Tau & 0.934 & 0.976 & 0.942 & 0.956 & 0.911 & 0.957 & 0.939 \\
OWPS-02 & Ben Tre & 0.962 & 0.931 & 0.964 & 0.951 & 0.920 & 0.937 & 0.981 \\
OWPS-03 & Binh Dinh & 0.983 & 0.916 & 0.981 & 0.969 & 0.962 & 0.913 & 0.992 \\
OWPS-04 & Binh Thuan & 1.000 & 0.902 & 1.000 & 1.000 & 1.000 & 0.884 & 1.000 \\
OWPS-05 & Ca Mau & 0.887 & 1.000 & 0.895 & 0.897 & 0.911 & 1.000 & 0.903 & \\
OWPS-06 & Ninh Thuan & 0.983 & 0.907 & 0.994 & 0.993 & 0.982 & 0.898 & 0.998 \\
OWPS-07 & Soc Trang & 0.962 & 0.916 & 0.977 & 0.969 & 0.962 & 0.921 & 0.977 \\
\hline
\end{tabular}

\section{References}

1. IRENA, I. Future of wind: Deployment, investment, technology, grid integration and socio-economic aspects. (2019).

2. Quang, V. D., Doan, V. Q., Dinh, V. N. \& Duc, N. D. Evaluation of resource spatial-temporal variation, dataset validity, infrastructures and zones for Vietnam offshore wind energy. Vietnam Journal of Science, Technology and Engineering 62, (2020).

3. Ha-Duong, M., Teske, S., Pescia, D. \& Pujantoro, M. Options for wind power in Vietnam by 2030. https://halenpc.archives-ouvertes.fr/hal-02329698 (2019).

4. Xuan Son, N. T. \& Thi Gam, P. Vietnam's Policy for Promoting Offshore Wind Power and Environmental Impact Assessment. Environmental Claims Journal (2021) doi:10.1080/10406026.2021.1932335.

5. Nguyen, X. P. et al. Mission, challenges, and prospects of renewable energy development in Vietnam. Energy Sources, Part A: Recovery, Utilization, and Environmental Effects (2021) doi:10.1080/15567036.2021.1965264.

6. Dinh, V. N. \& McKeogh, E. Offshore Wind Energy: Technology Opportunities and Challenges. in (2019). doi:10.1007/978-981-13-2306-5_1.

7. Doan, V. Q., Kusaka, H., Du, T. v., Nguyen, D. D. \& Cong, T. Numerical Approach for Studying Offshore Wind Power Potential Along the Southern Coast of Vietnam. in (2019). doi:10.1007/978-981-13-2306-5_33.

8. Toan, D. van, Doan, Q. van, le Duy Anh, P. \& Dinh, V. N. The Zoning of Offshore Wind Energy Resources in the Vietnam Sea. in (2019). doi:10.1007/978-981-13-2306-5_34.

9. Vo, H. T., Le, V. T., Phung, L. M. \& Cao, T. T. H. Offshore Wind Power in Vietnam: Lessons Learnt from Phu Quy and Bac Lieu Wind Farms. in (2019). doi:10.1007/978-981-13-2306-5_38.

10. Shao, M. et al. A review of multicriteria decision making applications for renewable energy site selection. Renewable Energy 157, 377-403 (2020).

11. Wang, C., Dang, T. \& Nguyen, N. Location Optimization of Wind Plants Using DEA and Fuzzy Multi-Criteria Decision Making: A Case Study in Vietnam. IEEE Access (2021) doi:10.1109/ACCESS.2021.3106281.

12. Fetanat, A. \& Khorasaninejad, E. A novel hybrid MCDM approach for offshore wind farm site selection: A case study of Iran. Ocean \& Coastal Management 109, 17-28 (2015).

13. Kaya, T. \& Kahraman, C. Multicriteria renewable energy planning using an integrated fuzzy VIKOR \& AHP methodology: The case of Istanbul. Energy 35, 2517-2527 (2010).

14. Ayodele, T. R., Ogunjuyigbe, A. S. O., Odigie, O. \& Munda, J. L. A multicriteria GIS based model for wind farm site selection using interval type-2 fuzzy analytic hierarchy process: The case study of Nigeria. Applied Energy 228, 1853-1869 (2018).

15. Ayodele, T. R., Ogunjuyigbe, A. S. O., Odigie, O. \& Jimoh, A. A. On the most suitable sites for wind farm development in Nigeria. Data in Brief 19, 29-41 (2018).

16. $\mathrm{Wu}, \mathrm{J}$., Huang, H. bin \& Cao, Q. wei. Research on AHP with interval-valued intuitionistic fuzzy sets and its application in multicriteria decision making problems. Applied Mathematical Modeling 37, 9898-9906 (2013). 
17. Wang, Z. J., Yang, X. \& Jin, X. T. And-like-uninorm-based transitivity and analytic hierarchy process with interval-valued fuzzy preference relations. Information Sciences 539, 375-396 (2020).

18. Kahraman, C., Öztayşi, B. \& Onar, S. C. Warehouse Location Design Using AS/RS Technologies: An Interval Valued Intuitionistic Fuzzy AHP Approach. in (2020). doi:10.1007/978-3-030-42188-5_19.

19. Wu, Y., Geng, S., Xu, H. \& Zhang, H. Study of decision framework of wind farm project plan selection under intuitionistic fuzzy set and fuzzy measure environment. Energy Conversion and Management 87, 274-284 (2014).

20. Wu, Y., Zhang, J., Yuan, J., Geng, S. \& Zhang, H. Study of decision framework of offshore wind power station site selection based on ELECTRE-III under intuitionistic fuzzy environment: A case of China. Energy Conversion and Management 113, 66-81 (2016).

21. Wu, Y. et al. A decision framework of offshore wind power station site selection using a PROMETHEE method under intuitionistic fuzzy environment: A case in China. Ocean E Coastal Management 184, 105016 (2020).

22. Junaid, M., Xue, Y., Syed, M. W., Li, J. Z. \& Ziaullah, M. A Neutrosophic AHP and TOPSIS Framework for Supply Chain Risk Assessment in Automotive Industry of Pakistan. Sustainability 12, (2019).

23. Yucesan, M. \& Gul, M. Failure modes and effects analysis based on neutrosophic analytic hierarchy process: method and application. Soft Computing 25, (2021).

24. Ilbahar, E., Karaşan, A., Cebi, S. \& Kahraman, C. A novel approach to risk assessment for occupational health and safety using Pythagorean fuzzy AHP \& fuzzy inference system. Safety Science 103, 124-136 (2018).

25. Ak, M. F. \& Gul, M. AHP-TOPSIS integration extended with Pythagorean fuzzy sets for information security risk analysis. Complex \& Intelligent Systems 5, (2019).

26. Mathew, M., Chakrabortty, R. K. \& Ryan, M. J. A novel approach integrating AHP and TOPSIS under spherical fuzzy sets for advanced manufacturing system selection. Engineering Applications of Artificial Intelligence 96, 103988 (2020).

27. Dogan, O. Process mining technology selection with spherical fuzzy AHP and sensitivity analysis. Expert Systems with Applications 178, 114999 (2021).

28. Kutlu Gündoğdu, F. \& Kahraman, C. A novel VIKOR method using spherical fuzzy sets and its application to warehouse site selection. Journal of Intelligent \& Fuzzy Systems 37, (2019).

29. Kutlu Gundogdu, F. \& Kahraman, C. Extension of WASPAS with Spherical Fuzzy Sets. Informatica 30, (2019).

30. Kutlu Gündoğdu, F. \& Kahraman, C. Spherical fuzzy sets and spherical fuzzy TOPSIS method. Journal of Intelligent \& Fuzzy Systems 36, (2019).

31. Kutlu Gündoğdu, F. \& Kahraman, C. A novel spherical fuzzy analytic hierarchy process and its renewable energy application. Soft Computing 24, (2020).

32. Zadeh, L. A. Fuzzy sets as a basis for a theory of possibility. Fuzzy Sets and Systems 1, 3-28 (1978).

33. Zadeh, L. A. The concept of a linguistic variable and its application to approximate reasoning - I. Information Sciences 8, 199-249 (1975).

34. Atanassov, K. T. More on intuitionistic fuzzy sets. Fuzzy Sets and Systems 33, 37-45 (1989).

35. Yager, R. R. Pythagorean fuzzy subsets. in 2013 Joint IFSA World Congress and NAFIPS Annual Meeting (IFSA/NAFIPS) 57-61 (IEEE, 2013). doi:10.1109/IFSA-NAFIPS.2013.6608375.

36. Kutlu Gündoğdu, F. \& Kahraman, C. A novel VIKOR method using spherical fuzzy sets and its application to warehouse site selection. Journal of Intelligent \& Fuzzy Systems 37, (2019).

37. Smarandache F. A unifying field in Logics: Neutrosophic Logic. Philosophy, American Research Press 1-141 (1999).

38. Grattan-Guinness, I. Fuzzy Membership Mapped onto Intervals and Many-Valued Quantities. Zeitschrift für Mathematische Logik und Grundlagen der Mathematik 22, (1976).

39. Zavadskas, E. K., Turskis, Z. \& Antucheviciene, J. Optimization of Weighted Aggregated Sum Product Assessment. Electronics and Electrical Engineering 122, (2012).

40. Hashemkhani Zolfani, S., Aghdaie, M. H., Derakhti, A., Zavadskas, E. K. \& Morshed Varzandeh, M. H. Decision making on business issues with foresight perspective; an application of new hybrid MCDM model in shopping mall locating. Expert Systems with Applications 40, (2013).

41. Zavadskas, E. K., Antucheviciene, J., Šaparauskas, J. \& Turskis, Z. Multicriteria Assessment of Facades' Alternatives: Peculiarities of Ranking Methodology. Procedia Engineering 57, (2013).

42. Bagočius, V., Zavadskas, K. E. \& Turskis, Z. Multi-Criteria Selection of a Deep-Water Port in Klaipeda. Procedia Engineering 57, (2013). 
43. Vafaeipour, M., Hashemkhani Zolfani, S., Morshed Varzandeh, M. H., Derakhti, A. \& Keshavarz Eshkalag, M. Assessment of regions priority for implementation of solar projects in Iran: New application of a hybrid multicriteria decision making approach. Energy Conversion and Management 86, (2014).

44. Badalpur, M. \& Nurbakhsh, E. An application of WASPAS method in risk qualitative analysis: a case study of a road construction project in Iran. International Journal of Construction Management 21, (2021).

45. Singh, R. K. \& Modgil, S. Supplier selection using SWARA and WASPAS - a case study of Indian cement industry. Measuring Business Excellence 24, (2020).

46. Nguyen, N. B. T., Lin, G.-H. \& Dang, T.-T. Fuzzy Multi-Criteria Decision-Making Approach for Online Food Delivery (OFD) Companies Evaluation and Selection: A Case Study in Vietnam. Processes 9, (2021).

47. Wang, C.-N., Nguyen, N.-A.-T., Dang, T.-T. \& Hsu, H.-P. Evaluating Sustainable Last-Mile Delivery (LMD) in B2C E-Commerce Using Two-Stage Fuzzy MCDM Approach: A Case Study From Vietnam. IEEE Access 9, (2021).

48. Chaouachi, A., Covrig, C. F. \& Ardelean, M. Multicriteria selection of offshore wind farms: Case study for the Baltic States. Energy Policy 103, 179-192 (2017).

49. Lo, H. W., Hsu, C. C., Chen, B. C. \& Liou, J. J. H. Building a grey-based multicriteria decision-making model for offshore wind farm site selection. Sustainable Energy Technologies and Assessments 43, 100935 (2021).

50. Kutlu Gündoğdu, F. \& Kahraman, C. A novel spherical fuzzy analytic hierarchy process and its renewable energy application. Soft Computing 24, 4607-4621 (2020).

51. Mathew, M., Chakrabortty, R. K. \& Ryan, M. J. A novel approach integrating AHP and TOPSIS under spherical fuzzy sets for advanced manufacturing system selection. Engineering Applications of Artificial Intelligence 96, 103988 (2020).

52. The map of the potential of offshore wind power in Vietnam. https://www.evwind.es/2020/05/19/vietnam-haspotential-for-160-gw-of-offshore-wind-energy/74789?fbclid=IwAR1vPMwSsNaPmh8wl1 WzCFy_mouswQpMjGOsnVNwOuN-Hc46RUAhOt4qQUU (2021).

53. Wang, C.-N., Nguyen, N.-A.-T., Dang, T.-T. \& Bayer, J. A Two-Stage Multiple Criteria Decision Making for Site Selection of Solar Photovoltaic (PV) Power Plant: A Case Study in Taiwan. IEEE Access 9, (2021).

54. Zhang, X., Lu, J. \& Peng, Y. Hybrid MCDM Model for Location of Logistics Hub: A Case in China Under the Belt and Road Initiative. IEEE Access 9, (2021).

55. Liu, J., Xu, F. \& Lin, S. Site selection of photovoltaic power plants in a value chain based on grey cumulative prospect theory for sustainability: A case study in Northwest China. Journal of Cleaner Production 148, 386-397 (2017).

56. Hwang, C.-L. \& Yoon, K. Methods for Multiple Attribute Decision Making. in (1981). doi:10.1007/978-3-64248318-9_3.

57. Stanujkic, D., Z. E. K., G. M. K., \& T. Z. An extension of the EDAS method based on the use of interval grey numbers. Studies in Informatics and Control 26, 5-12 (2017).

58. Yazdani, M., Zarate, P., Kazimieras Zavadskas, E. \& Turskis, Z. A combined compromise solution (CoCoSo) method for multicriteria decision-making problems. Management Decision 57, (2019). 


\section{Supplementary Files}

This is a list of supplementary files associated with this preprint. Click to download.

- Supplementarylnfo.docx 